Article

\title{
Empirical Investigation of the Hygrothermal Diffusion Properties of Permeable Building Membranes Subjected to Variable Relative Humidity Condition
}

\author{
Toba Samuel Olaoye ${ }^{1, * \mathbb{D}}$, Mark Dewsbury ${ }^{1(\mathbb{D})}$ and Hartwig Künzel ${ }^{2}$ \\ 1 School of Architecture and Design, University of Tasmania, Inveresk, Launceston 7250, Australia; \\ mark.dewsbury@utas.edu.au \\ 2 Fraunhofer Institute for Building Physics IBP, Fraunhoferstr. 10, 83626 Valley, Germany; \\ hartwig.kuenzel@ibp.fraunhofer.de \\ * Correspondence: toba.olaoye@utas.edu.au; Tel.: +61-40-6277304
}

\section{check for} updates

Citation: Olaoye, T.S.; Dewsbury, M.; Künzel, H. Empirical Investigation of the Hygrothermal Diffusion

Properties of Permeable Building Membranes Subjected to Variable Relative Humidity Condition. Energies 2021, 14, 4053. https:// doi.org/10.3390/en14134053

Academic Editors: Paula

Fernández González and María José Presno

Received: 20 May 2021

Accepted: 2 July 2021

Published: 5 July 2021

Publisher's Note: MDPI stays neutral with regard to jurisdictional claims in published maps and institutional affiliations.

Copyright: (c) 2021 by the authors. Licensee MDPI, Basel, Switzerland. This article is an open access article distributed under the terms and conditions of the Creative Commons Attribution (CC BY) license (https:/ / creativecommons.org/licenses/by/ $4.0 /)$.

\begin{abstract}
Hygrothermal modelling is increasingly used to inform building envelope design. A key input for these calculations is the material's vapour diffusion properties. Respecting a growing international concern, this research has questioned the appropriateness of the current test method to establish construction material for vapour diffusion properties. This article reports on the empirical measurement of the vapour diffusion properties of two vapour-permeable building membranes commonly used in Australia residential systems when subjected to variable relative humidity conditions. The method involved completing dry cup and wet cup standard tests as specified in ISO $12572,\left(23{ }^{\circ} \mathrm{C}\right.$ and $50 \%$ relative humidity $\left.\mathrm{RH}\right)$. Further tests were then conducted as temperature remained at $23{ }^{\circ} \mathrm{C}$ but the relative humidity changed to $35 \%, 65 \%$ and $80 \%$, respectively, in order to know if the diffusion properties are the same or change with varying relative humidity. The results from the wet cup and dry cup tests under different relative humidity conditions were non-linear and different. These results indicate vapour-permeable membranes behave differently when exposed to different relative humidity conditions. In conclusion, this research demonstrates that the current vapour resistivity test method is inadequate, hence the need to establish more detailed diffusion resistivity properties in different humidity ranges that represent conditions experienced within a building's external envelope.
\end{abstract}

Keywords: hygrothermal analysis; interstitial condensation; mould; diffusion resistivity; energy efficiency; moisture management; permeable building membranes; varying relative humidity

\section{Introduction}

This research has sought to investigate the sufficiency of the current standard testing method for establishing the water vapour diffusion properties of construction materials through laboratory measurement. This research has resulted from international concern over the current single point vapour diffusion test method's adequacy to represent the conditions materials' experience within an external envelope and, by inference, the need for more detailed hygrothermal diffusion properties for construction materials in different relative humidity and temperature ranges [1-4]. Over many years, the two international standards, ASTM E96m and ISO 12572, have prescribed a single temperature of $23{ }^{\circ} \mathrm{C}$ $\left( \pm 1{ }^{\circ} \mathrm{C}\right)$ and a relative humidity $50 \%( \pm 5 \%)$ for conducting the gravimetric water vapour transmission laboratory testing for construction materials [5,6]. Although these standards have been regularly revised over time, the reality and the demand for modern, healthy and energy efficient homes within our world's very diverse climates is causing a paradigm shift about the understanding of high-performance building envelope systems' hygrothermal analysis [7-9]. The problems associated with high indoor humidity, condensation, and mould growth currently prevalent in Australia buildings' cold and humid climate is 
common in many developing and developed nations, and high-quality material vapour diffusion data is needed to undertake hygrothermal simulations to inform regulatory development [9-11]. Considering the global movement towards a zero-carbon economy and its reliance on highly energy-efficient buildings, it is important to acknowledge that airtight and well-insulated envelopes can perform sub-optimally if unmanaged moisture is present [12-17]. Aside from building durability issues, this will further affect opportunities to reduce carbon emissions generated through the operation of heating and cooling equipment within buildings $[18,19]$.

One approach to address this problem is to acknowledge the impact of varying indoor water vapour diffusion processes in building envelope [20,21]. The powerful forces of vapour diffusion are caused, to a large extent, by the varying vapour pressure gradients that exist within the interior and exterior of the building envelope [16,22]. As relative humidity is one of the critical factors driving the vapour gradient, it is essential to consider the impact of different relative humidity on construction materials rather than the single RH $(50 \%$ RH) specified by the standard for testing $[19,23]$.

To test the hypothesis that the single point test method may be insufficient for testing construction materials, a dynamic laboratory vapour resistivity testing method was proposed. A dynamically controlled test room would enable the measurement of construction material water vapour diffusion properties at various temperatures and relative humidities. By applying this new testing regime, it would establish if different temperature and different relative humidity conditions affect the water vapour diffusion properties of construction materials. the implication being that, if material water vapour diffusion properties vary based on changing temperature and relative humidity conditions, then the current single point test method is inadequate for providing appropriate data for hygrothermal simulation. Additionally, hygrothermal simulation results using data from the single point test method may provide incorrect guidance for envelope design.

Building membranes have become essential components of building envelopes due to the many roles they play in modern construction systems, especially in framed construction $[22,24]$. They are used as an air control layer, a protection for bulk insulation- thermal control layers, as a water control layer and as a vapour control layer [2,25]. In Australia's temperate climates, early research has recommended building membranes as the most critical construction material likely to play a pivotal role in managing water vapour diffusion, moisture accumulation and mould growth within the building envelope [26-29]. This critical role that building membranes provide in external envelopes constructed from an insulated structural frame has also been identified in other developed nations [25]. Since 2003, building membranes have been increasingly used in Australia to meet the regulatory requirements for better insulated and air-sealed building envelopes. However, much of the market has been dominated by reflective and non-reflective vapour impermeable products. Many of these reflective products have provided inflated insulation properties as a cheaper option to meet the energy efficiency regulations. However, the application of membranes with a climatically inappropriate vapour resistivity has been identified as a major contributory factor to recent increases in condensation and mould in Australian stand-alone and multi-residential buildings.

Water vapour resistivity is a physical property of a material that is used to describe the material's capacity to allow or resist water vapour diffusion, and it is obtained through laboratory measurement [30]. This property is essential for appropriate classification of building membranes. The general classification may include permeable, semi-permeable, semi-impermeable and impermeable, and each of these classifications is often generically specified for vapour control membranes in different climate types [28]. Additionally, the membrane may be applied to timber or steel framed subfloors, walls and unconditioned attic roof spaces. While a vapour-impermeable membrane may be suitable as a water control layer in a vented roof space, a vapour-permeable membrane may be necessary to provide thermal, vapour and air control layer functions in steel and timber framed walls. In Australia's temperate climates, when a building membrane is applied to the 
external surface of an insulated steel or timber structural framed wall, it needs to allow the water vapour diffusion to be dynamically controlled from its warm side to its cool side (predominantly from the interior to the exterior), whereas, in Australia's warm and humid climates, when a building membrane is applied to the external surface of an insulated steel or timber framed wall, this should predominantly control water vapour diffusion in a dynamic way from the exterior to the interior. This implies that a building membrane applied to the façade of a building may perform many simultaneous functions. Hence, it is essential to understand the statutory and non-statutory functions of building membranes prior their application in construction system [2].

In 2015, the Australian Standard for Pliable Membranes (AS4200) identified the need for the detailed inclusion of water vapour diffusion properties for all building membranes. The standard provided two methods of vapour diffusion classification; the first was a general classification, as shown below in Table 1, while the second was a tested and published water vapour diffusion property in metric value. This required all building membrane manufacturers to provide the vapour resistivity properties of their products through appropriate labelling. As the final updated version of the vapour diffusion requirement did not require manufacturers to specifically declare the vapour diffusion value, many manufacturers only applied the general classification on labelling (as shown below in Table 1).

Table 1. Vapour control membrane general classification.

\begin{tabular}{|c|c|c|c|}
\hline $\begin{array}{c}\text { Vapour } \\
\text { Impermeable }\end{array}$ & $\begin{array}{c}\text { Vapour } \\
\text { Semi-Impermeable }\end{array}$ & $\begin{array}{c}\text { Vapour } \\
\text { Semi-Permeable }\end{array}$ & Vapour Permeable \\
\hline Polyethylene & Oil based paints & Wood & $\begin{array}{c}\text { Unpainted, paper-faced } \\
\text { plasterboard }\end{array}$ \\
\hline Vinyl & $\begin{array}{l}\text { Some vinyl wall } \\
\text { coverings }\end{array}$ & Plywood & Unpainted plaster \\
\hline Glass & Extruded polystyrene & $\begin{array}{l}\text { Expanded } \\
\text { polystyrene }\end{array}$ & $\begin{array}{c}\text { Bulk insulation (rock wool, } \\
\text { glass wool and polyester) }\end{array}$ \\
\hline Sheet metal & $\begin{array}{l}\text { Paper-facedbulk } \\
\text { insulation }\end{array}$ & Most plastic paints & $\begin{array}{l}\text { Cellulose insulation, } \\
\text { timber, clay bricks and } \\
\text { concrete blocks }\end{array}$ \\
\hline
\end{tabular}

A preliminary market survey that was conducted in 2018 and 2019 as a part of this research revealed that some products had no vapour diffusion information on packaging, whilst others had material property data sheets, which only indicate the general AS4200 2017 classification of their product.

Furthermore, the condensation requirements within the national building regulations, the National Construction Code (NCC), only refer to the pliable membranes as described in AS4200.1, and there is no vapour diffusion requirement described for other materials used in the external envelope [28,31]. Within AS4200.1, the American Standard for Standard Test Methods for Water Vapor Transmission of Materials E96M is referenced as the only method to quantify the vapour diffusion properties of building membranes. Additionally, Australian Standard 4200.1 is the only Australian guidance document that describes the requirement for water vapour diffusion and condensation control within buildings. This does not adequately recognise or describe the hygrothermal function of pliable membranes (or other materials) and how they should be considered as a critical component in the envelope design and construction process. This lack of adequate, well-prescribed and legislated performance requirements may be responsible for the failure of manufacturers to include adequate water vapour diffusion properties for their products. Consequently, this lack of appropriate specification of vapour diffusion properties for building membranes or other elements may create a distinct challenge for researchers and design professionals who may want to undertake energetic hygrothermal simulations to inform building envelope design and performance. Furthermore, for a building membrane 
to provide a climatically appropriate function as an interstitial vapour control layer, it must have climatically appropriate rates of water vapour diffusion.

Considering all the above, the appropriate application of building membranes can play a pivotal role in the management of water vapour diffusion in new timber- and steel-framed, energy-efficient buildings. The establishment of their static or dynamic diffusion properties essential for informing long-term transient hygrothermal simulation is imperative. Therefore, this paper reports the results from experiments completed to investigate the impact of different relative humidity conditions on the water vapour diffusion properties of building membranes commonly used in the external envelope of Australian housing. The study is expected to provide recommendations about the most appropriate method and procedures to establish the water vapour diffusion properties for construction materials and, by reflection, provide guidance to regulators and policy makers regarding construction material vapour diffusion properties required for hygrothermal modelling in Australia.

\section{Materials and Methods}

The methodology for this research is discussed in this section. This involved completing laboratory measurement of the water vapour diffusion properties of two permeable, pliable building membranes commonly used in Australian external envelope systems. Four experiments were conducted, which lasted for the period of one year. During the experiment periods, the temperature was maintained at $23^{\circ} \mathrm{C}$. The unique aspect of the research involved the testing of vapour diffusion properties under four different relative humidity conditions, namely $35 \%, 50 \%, 65 \%$ and $80 \%$. The procedures employed for these experiments are discussed below.

\subsection{Hygrothermally Controlled Test Room Operation and Climatic Condition Parameters}

A very crucial aspect of this research involved establishing, operating and controlling the temperature and relative humidity with a hygrothermal test room. The details of the construction of the hygrothermal test room, the control and the stabilization of the internal environment is previously published [10]. This laboratory was validated through a round-robin test, which was carried out with Fraunhofer Institute for Building Physics IBP Germany in accordance with international guidelines [6]. The temperature variation did not exceed $\pm 2{ }^{\circ} \mathrm{C}$, and the relative humidity variation did not exceed $\pm 5 \%$. In each scenario, material water vapour diffusion was measured from dry cup and wet cup methods.

\subsection{Selection of Pliable Building Membranes}

The research program included the empirical measurement of water vapour diffusion from permeable, impermeable and variable pliable membrane products. This article focusses on the results from two vapour-permeable products.

The materials tested for this research were locally sourced, pliable building membranes commonly used in Australia for air tightness and water barrier purposes on steel and timber framed buildings. Even though these membranes were locally sourced, they are incorporated, internationally distributed and locally rebranded products. The two pliable membranes discussed here have similar polymer characteristic and are considered as vapour-open materials. Membrane A is an ultraviolet-stabilised, tear-resistant polyolefin polymer, while membrane B is made of thermoplastic elastomer ethyl ester polymer with an ultraviolet stability capacity of up to 180 days. The water vapour permeability of the selected pliable membranes is categorized as Class 4 within Australian Standard 4200.1 [25], as shown in Table 2. 
Table 2. AS4200 vapour per classifications.

\begin{tabular}{cccc}
\hline \multicolumn{4}{c}{ Vapour Permeance (See Note) $\boldsymbol{\mu g} / \mathbf{N} . \mathbf{s}$} \\
\hline Class & VCM category & Min. $(\geq)$ & Max. $(<)$ \\
Class 1 & Vapour barrier & 0.0000 & 0.0022 \\
Class 2 & & 0.0022 & 0.1429 \\
Class 3 & Vapour-permeable & 0.1429 & 1.1403 \\
Class 4 & ASTM-E96 Method B Wet Cup-23 ${ }^{\circ} \mathbf{C ~ 5 0 \% \mathbf { R H }}$ \\
&
\end{tabular}

\subsection{Gravimetric Measurement}

Gravimetric measurement of the vapour diffusion requires the regular, time-based measurement of the test dish mass to enable a calculation of materials water vapour diffusion properties. This can be determined through a wet cup or dry cup method. To quantify the amount of water vapour diffusion, different relative humidity conditions are established on either side of the material being tested. The temperature on both sides of the material is the same. For this research, the temperature within and outside the test dishes was maintained at $23^{\circ} \mathrm{C}$. The relative humidity established outside the test dishes was maintained at $35 \%$ for the first, $50 \%$ for the second, $65 \%$ for the third and $80 \%$ for the fourth experiment.

In this research, ten specimens of each material were prepared for testing: five as wet cup and five as dry cup. The test dishes used were round, $60 \mathrm{~mm}$ deep, with a diameter of $200 \mathrm{~mm}$, as shown in Figure 1. The wet cup method used a saturated solution of ammonium dihydrogen phosphate within each dish to attain a desired humidity of 93\% within the test dishes, as shown in Figure 2. The dry cup method used a silica gel bead in the dish to attain a desired relative humidity value of $3 \%$, as shown in Figure 3. In all cases, a $20 \mathrm{~mm}$ air space was maintained between the top surface of the chemical and the bottom surface of the test specimen. Initially, this research used distilled water, as recommended by ASTM E $96 \mathrm{~m}$, as 100\% relative humidity solution for wet cup testing. However, condensation was observed forming around the bottom surface of the material being tested, which would significantly impact the measurement of the test dish mass. Subsequently, the use of distilled water was discontinued.

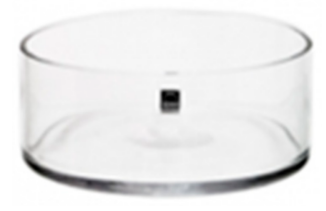

Figure 1. Example of $60 \mathrm{~mm}$ round glass dish.

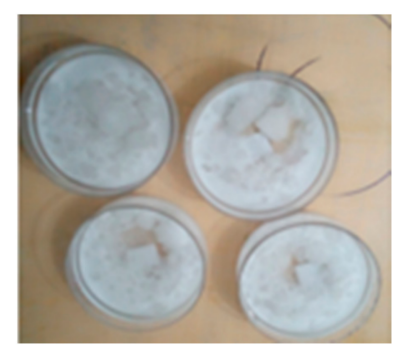

Figure 2. Glass dishes for wet cup test with saturated ammonium dihydrogen phosphate. 


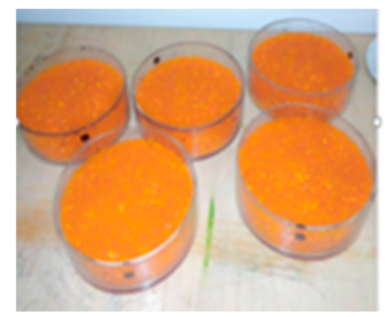

Figure 3. Glass dishes for dry cup test with silica gel beads.

Each pliable membrane was glued to the top edge of the test dish, and the intersection between the membrane and this dish was taped with paper tape and sealed with paraffin wax, as shown in Figure 4. This sealing process is to ensure that no air can leak between the test dish and the material being tested. The first weighing of the assembled and sealed test dish to establish a bass value for mass was taken and recorded immediately after the wax sealing. Regular weighing of each test dish mass was taken every two hours until the equilibrium was achieved, as shown in Figure 5. The dishes were than stored on the shelves within the test room, as shown in Figure 6. This same procedure was applied in all four experiments.

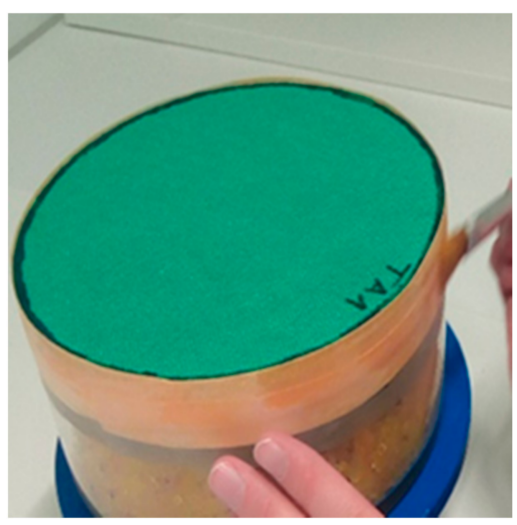

Figure 4. Taping and wax sealing.

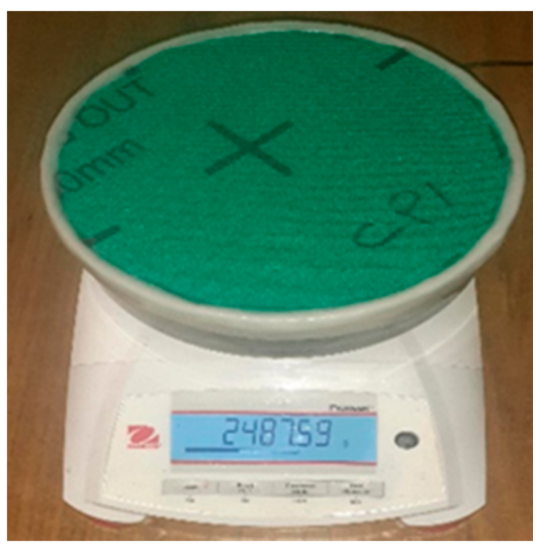

Figure 5. Weighing of cup assembly. 


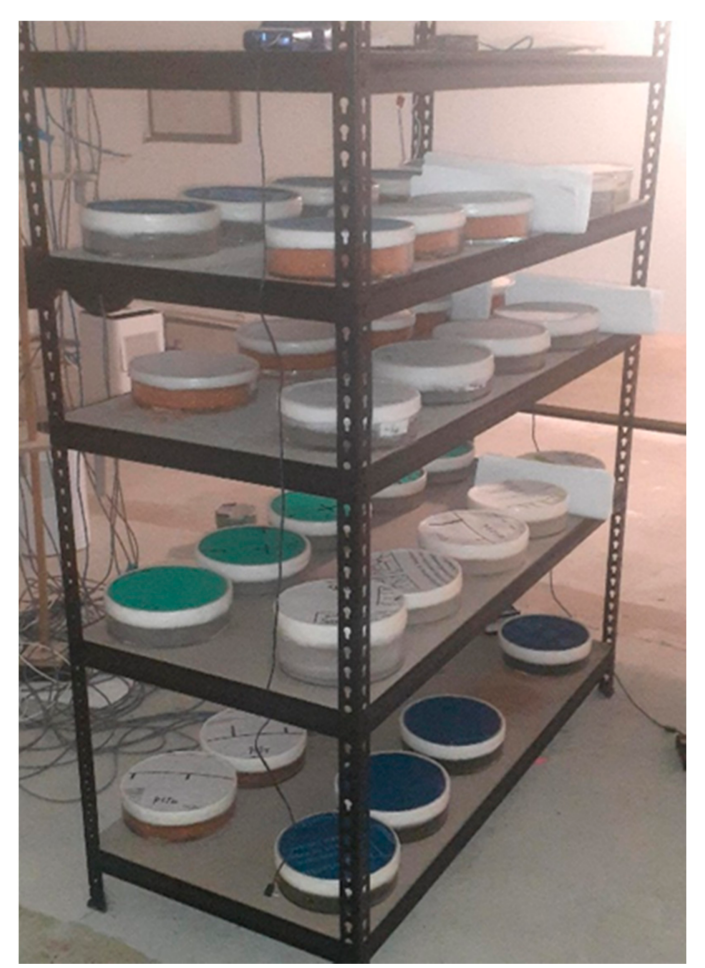

Figure 6. Shelving of dishes within test room.

\subsection{Mathematical Equation and Water Vapour Diffusion Resistivity Properties Calculation}

The mathematical equations provided in EN ISO 12572 [26] were used for calculating water vapour resistivity properties of the specimen after the successful gravimetric measurement and are presented as follows in [6]:

$$
\text { Water vapour flux } \mathrm{g}=\mathrm{G} / \mathrm{A} \text { in } \mathrm{kg} /\left(\mathrm{s} \cdot \mathrm{m}^{2}\right)
$$

A is the arithmetic mean of the exposed area of the test specimen in $\mathrm{m}^{2}$.

$\mathrm{G}$ is the slope of the straight line, $\mathrm{g} / \mathrm{s}$, or the regression line between the mass change rate over the time interval [6].

The water permeance $\mathrm{W}$ is defined in terms of a vapour pressure difference, and it indicates the rate of vapour diffusion through a unit area of a material during a given period of time under a specific temperature and relative humidity [6].

$$
\mathrm{W}=\mathrm{g} / \Delta \mathrm{pv} \text { in } \mathrm{kg} /\left(\mathrm{s} . \mathrm{m}^{2} \cdot \mathrm{Pa}\right)
$$

where, $\Delta p v$ is the is the difference in the partial vapour pressure, $\mathrm{P}_{\text {sat }}$, of each side of the test specimen $\left(\mathrm{P}_{\mathrm{sat}}=\varphi \cdot 610.5 \cdot \mathrm{e} 17.269 \cdot \theta / 237.3+\theta\right)$. RH [6].

Thus, $\Delta \mathrm{pv}=\mathrm{P}_{\text {sat }}$ wet side $-\mathrm{P}_{\text {sat }}$ dry side, where $\theta$ is the temperature, and $\varphi$ is the

The water vapour resistance $Z$ is the reciprocal of water vapour permeance, which is represented mathematically as in [6]:

$$
\mathrm{Z}=1 / \mathrm{W} \text { in }\left(\mathrm{s} \cdot \mathrm{m}^{2} \cdot \mathrm{Pa}\right) / \mathrm{kg}
$$

The water vapour permeability $\delta$, which is also a function of temperature and relative humidity, is the arithmetic product of permeance and thickness of a tested specimen; thus, it is calculated as:

$$
\delta=\mathrm{W} \times \mathrm{d} \text { in } \mathrm{kg} /(\mathrm{s} \cdot \mathrm{m} \cdot \mathrm{Pa} .)
$$

where $\mathrm{d}$ is the mean thickness of the test specimen measured with a micrometre screw gauge [6]. 
The water vapour resistance factor and the air layer equivalent are very essential properties needed for hygrothermal simulation. Resistance factor $\mu$ can be calculated using the equation as follows:

$$
\text { Water vapour resistance factor } \mu=\delta a / \delta
$$

where $\delta a$ is the water vapour permeability of air around the laboratory site, while the water vapour permeability of air at $23^{\circ} \mathrm{C}$ is extrapolated from the graph shown in Figure 7 , from ISO 12572. This is only completed once the mean barometric pressure of the site during the period of the measurement has been obtained [6].

The ISO 12572 requires the inclusion of the barometric pressure of the testing site during the testing period [6]. In this research, the barometric pressure was obtained from the Australian Bureau of Meteorology observations at the Low Head weather station, which is approximately $40 \mathrm{~km}$ from Launceston. This was selected due to its proximity to mean sea level, which corresponds to the height of the test building at Launceston. Given that the barometric pressure is not always constant, Table 3 show the average barometric pressure during each experiment, while Table 4 shows the other input parameters used for calculation purposes.

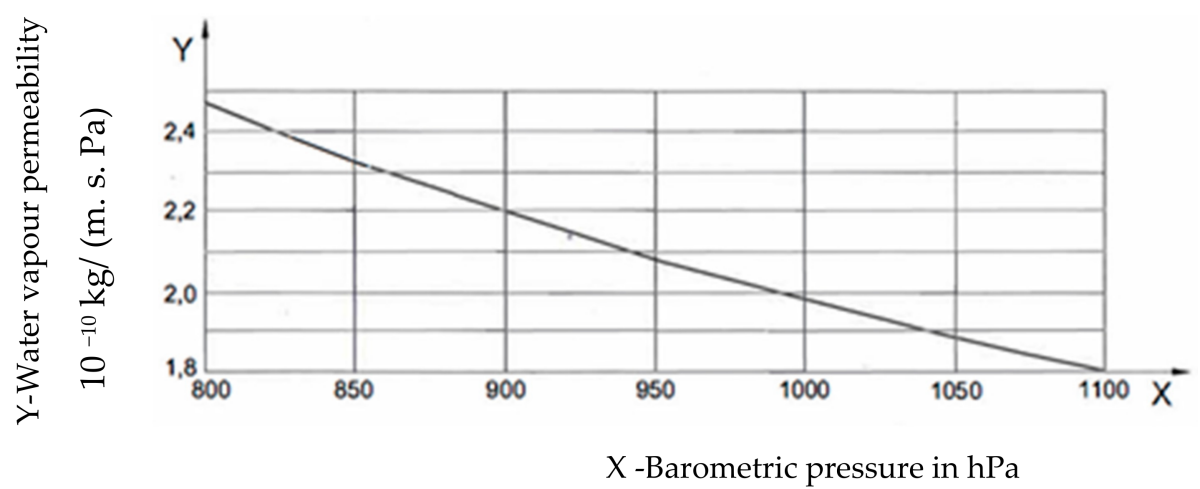

Figure 7. Water vapour permeability of air as a function of barometric pressure at $23^{\circ} \mathrm{C}$.

Finally, the water vapour diffusion equivalent, air layer thickness, is denoted by $S_{d}$ and calculated as [6]:

$$
\mu \times d
$$

Table 3. Summary of the average barometric pressure $(\mathrm{hPa})$ from each experiment.

\begin{tabular}{ccccc}
\hline Method & $\begin{array}{c}\text { Test Period 1 } \\
\mathbf{( 3 5 \% )}\end{array}$ & $\begin{array}{c}\text { Test Period 2 } \\
\mathbf{5 0 \% )}\end{array}$ & $\begin{array}{c}\text { Test Period 3 } \\
\mathbf{( 6 5 \% )}\end{array}$ & $\begin{array}{c}\text { Test Period 4 } \\
\mathbf{( 8 0} \%)\end{array}$ \\
\hline & & Material 1(A) & & \\
Dry test & 1025.03 & 1030.5 & 1020.40 & 1033.46 \\
Wet test & 1014.26 & 1020.35 & 1017.27 & 1022.5 \\
& & Material 2 (B) & 1014.7 & 1033.1 \\
Dry test & 1013.6 & 1030.1 & 1022.1 & 1022.5 \\
Wet test & 1022.23 & 1030.03 & & \\
\hline
\end{tabular}

Table 4. Required calculation parameters.

\begin{tabular}{cc}
\hline Parameter & Values \\
\hline Dishes & Round glass dish $(60 \times 195 \mathrm{~mm})$ \\
Air space & $20 \mathrm{~mm}$ \\
Water vapor permeability of air & $1.92 \times 10^{-10} \mathrm{~kg} /(\mathrm{m} \cdot \mathrm{s} \cdot \mathrm{Pa})$ \\
\hline
\end{tabular}




\section{Results}

This section discussed the results from each section of the methodology above. The measured environmental conditions within the test building are presented first, followed by the results from the water vapour diffusion measurements.

\subsection{Results from Hygrothermally Controlled Test Room Conditioning}

During the material testing period for the four experiments, the temperature setpoint of the hygrothermal test room was maintained at $23^{\circ} \mathrm{C}$. Due to the observed variability of the tested materials vapour diffusion properties, the first experiment lasted for 3 months. The second vapour diffusion materials test lasted for 7 weeks, while the third and the fourth vapour diffusion materials testings both lasted for 4 weeks. Figures A1-A4 in the Appendix A show the temperature profiles that were measured within the environmentally controlled test room during each of the four material testing periods. Figures 8-11 show the box plot graphs for the measured temperature during each of the four testing periods. In each case, the blue box plot shows the observations from three temperature sensors located $1800 \mathrm{~mm}$ above the floor. The orange box plot shows the observations from three temperature sensors located $1200 \mathrm{~mm}$ above the floor. The grey box plot shows the observations from three globe temperature (mean radiant) sensors located $1200 \mathrm{~mm}$ above the floor. The yellow box plot shows the observations from three temperature sensors located $600 \mathrm{~mm}$ above the floor. These figures indicate that, aside from occasional outliers, the temperature in the room for the first experiment was maintained between $22.1^{\circ} \mathrm{C}$ and $23.0^{\circ} \mathrm{C}$, with an average of $22.50{ }^{\circ} \mathrm{C}\left( \pm 0.9^{\circ} \mathrm{C}\right.$ standard deviation). During the second experiment, the room was maintained between $23.2^{\circ} \mathrm{C}$ and $22.6^{\circ} \mathrm{C}$, with an average of $22.9^{\circ} \mathrm{C}\left( \pm 0.5^{\circ} \mathrm{C}\right.$ standard deviation). In the third experiment, the temperature in the room was maintained between $23.0^{\circ} \mathrm{C}$ and $23.5^{\circ} \mathrm{C}$, with an average of $23.12{ }^{\circ} \mathrm{C}\left( \pm 0.5^{\circ} \mathrm{C}\right.$ standard deviation), while in the last experiment, the room temperature was maintained between $22.3^{\circ} \mathrm{C}$ and $23.7^{\circ} \mathrm{C}$, with an average of $22.73^{\circ} \mathrm{C}\left( \pm 1^{\circ} \mathrm{C}\right.$ standard deviation).

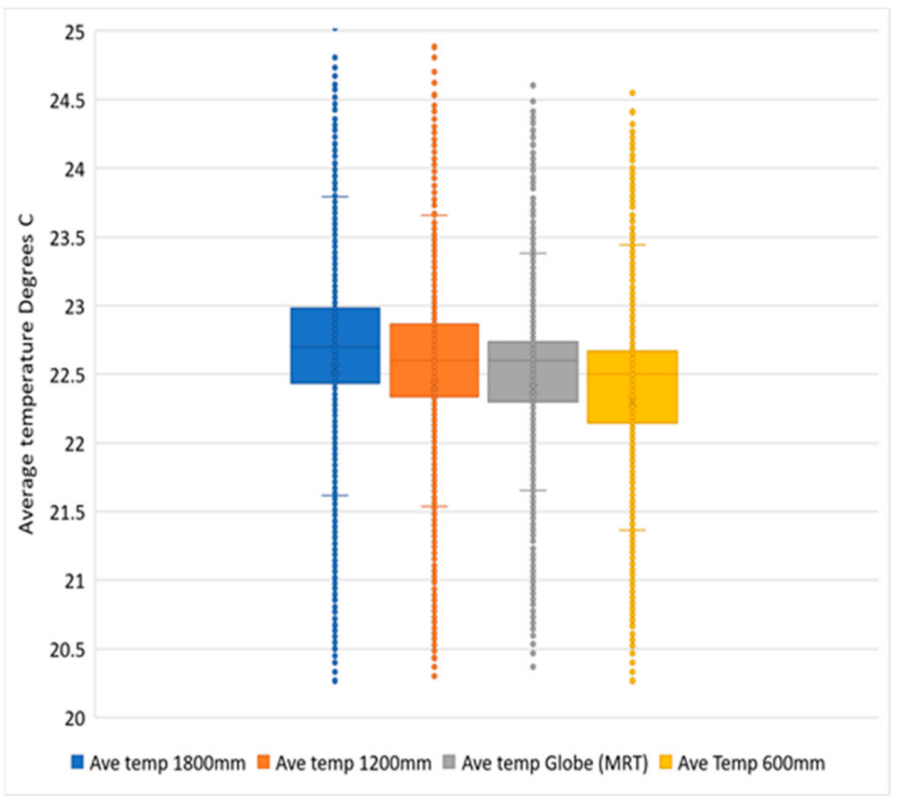

Figure 8. Box and whisker plot of temperature observations during test 1 . 


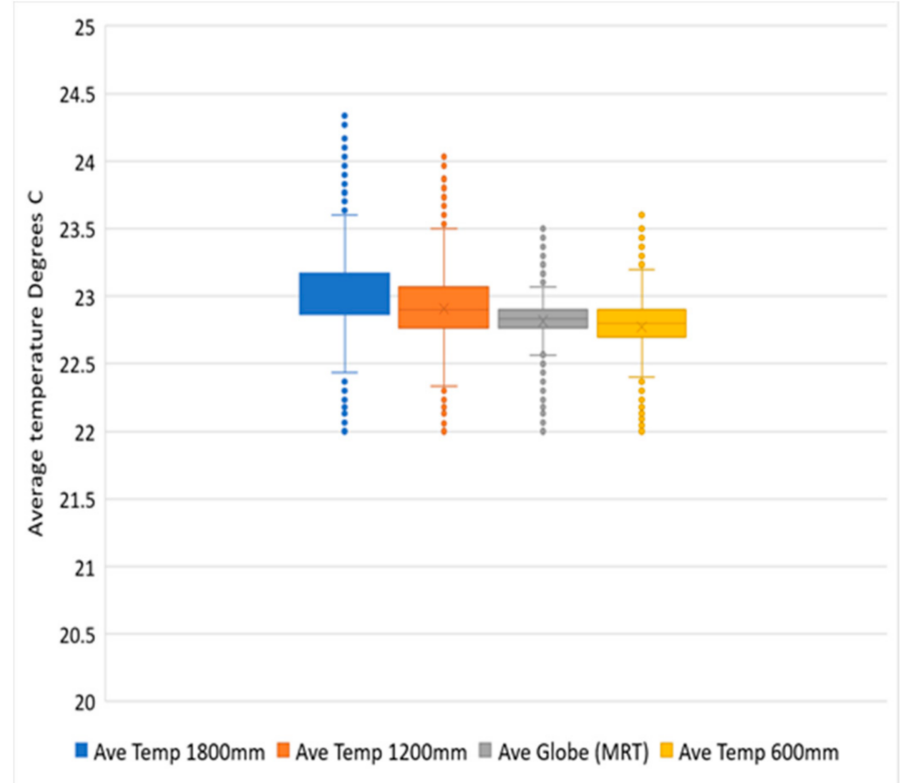

Figure 9. Box and whisker plot of temperature observations during test 2 .

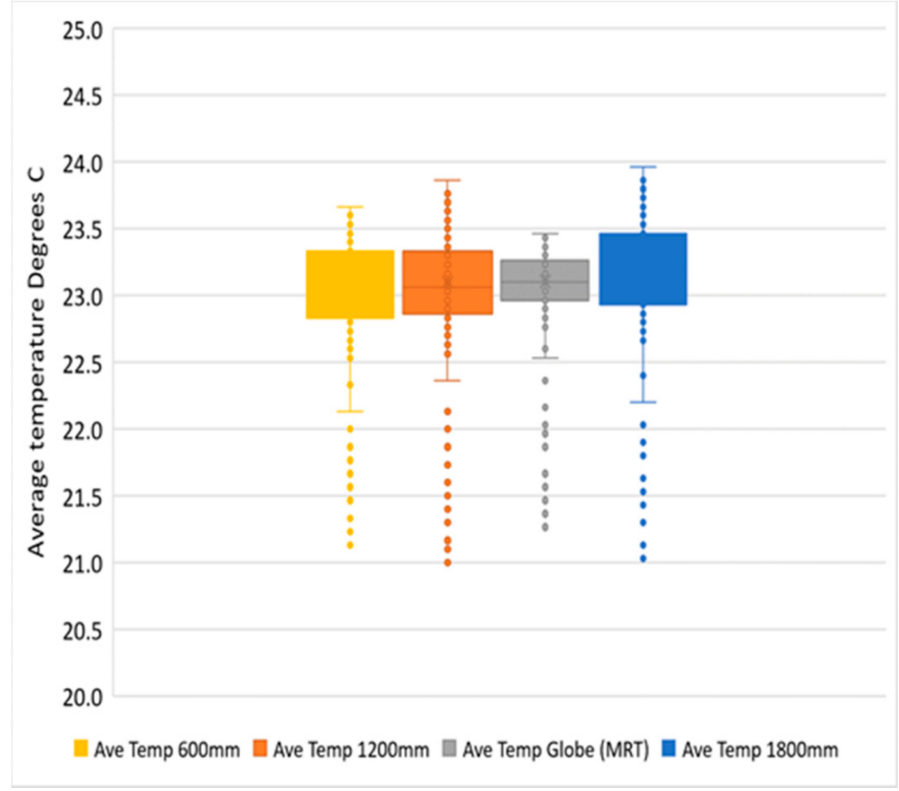

Figure 10. Box and whisker plot of temperature observations during test 3 . 


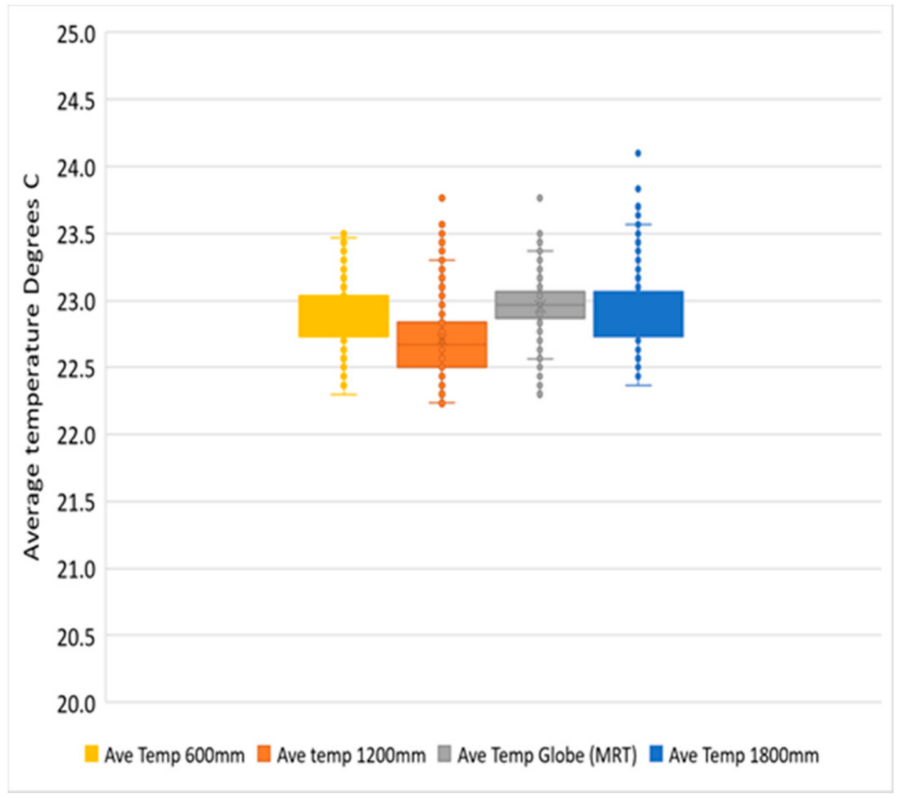

Figure 11. Box and whisker plot of temperature observations during test 4 .

The control of amount water vapour within the hygrothermal room was a crucial element for the relative humidity set points for each of the four vapour diffusion experiments. Figures A5-A8 in the Appendix A show the measured relative humidity within the test room during the four material testing periods. Figures $12-15$, below, show the box plot graphs of the measured room relative humidity during each material testing period of the experiment. The blue, orange and grey box plots show the results from the three relative humidity sensors located at mid room height $(1200 \mathrm{~mm})$. These figures show that, aside from occasional outliers, the relative humidity was maintained between:

- $\quad 35.0 \%$ to $36.9 \%$, with an average of $36 \%$ in the first test period;

- $\quad 49.8 . \%$ to $50.8 \%$, with an average humidity of $50.4 \%$ in the second test period;

- $\quad 64.5 \%$ to $65.2 \%$, with an average relative humidity of $65.12 \%$ in the third test period; and

- $\quad 77.84 \%$ to $83.2 \%$, with an average relative humidity of $80.29 \%$ in the fourth test period.

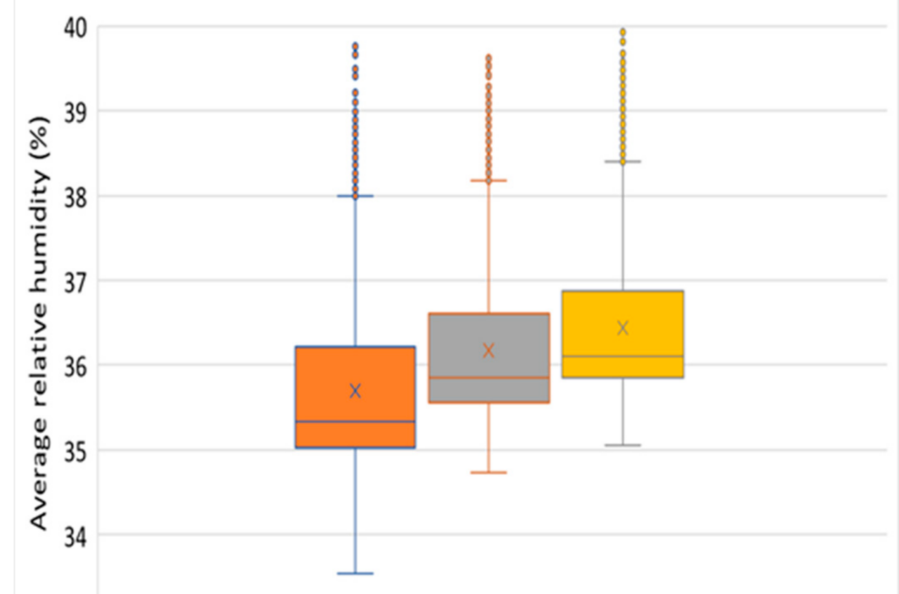

33

$\square$ RH Sensor $1 \square R H$ Sensor $2 \square$ RH Sensor 3

Figure 12. Box and whisker plot of relative humidity observations during test 1 . 


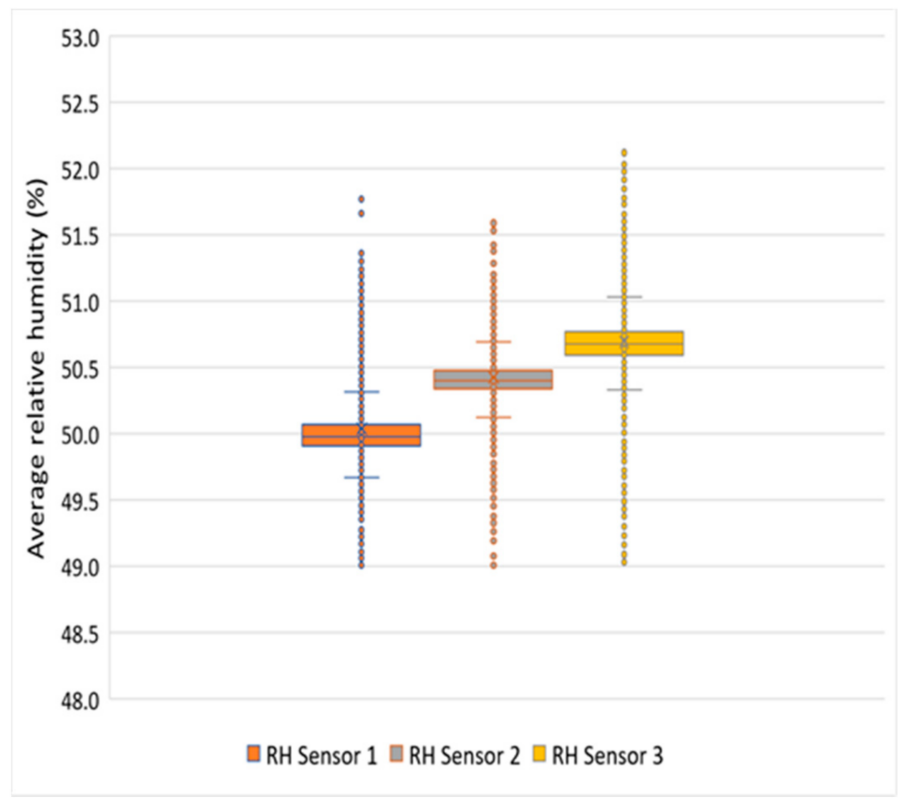

Figure 13. Box and whisker plot of relative humidity observations during test 2 .

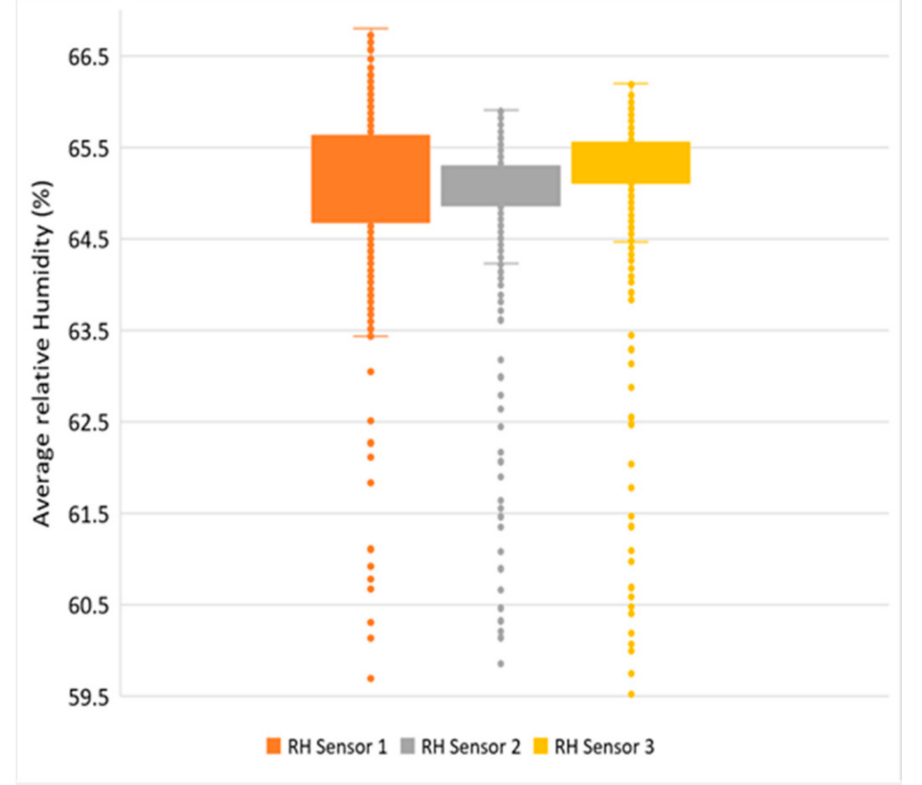

Figure 14. Box and whisker plot of relative humidity observations during test 3 . 


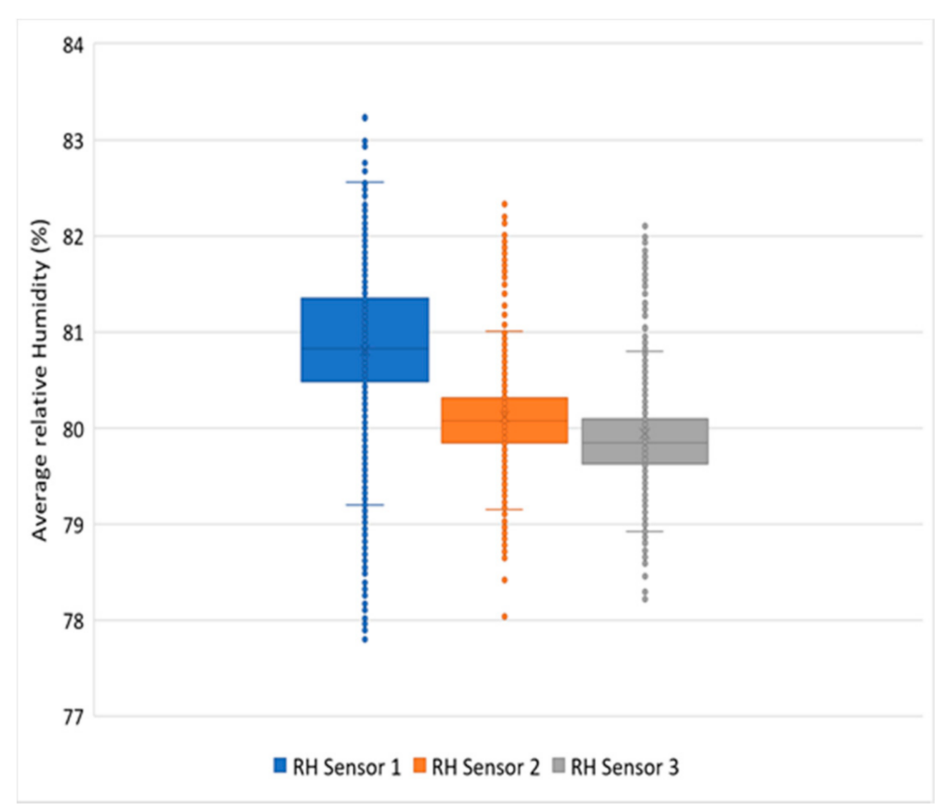

Figure 15. Box and whisker plot of relative humidity observations during test 4 .

\subsection{Results of the Water Vapour Resistivity Properties}

The gravimetric measurement of change in mass over a particular period began with the first measurement as soon as the dishes were placed in the test room. Subsequently, for the majority of each day, weighing was completed at two hourly intervals, and this was continued until it was observed that no further changes in mass occurred. This method established if the dish gained or lost weight (depending on the dry cup or wet cup chemical substrate), subject to the dish contents absorbing or releasing water, in a vapour form. The calculation method required the selection of the five most consistent measured changes in mass that occur during a 48-hour period for each material testing cycle. Tables 5 and 6 , below, show the average total difference in mass measured during an appropriate $48 \mathrm{~h}$ for tested materials A and B, respectively.

Table 5. Moisture measurement for Sample A over $48 \mathrm{~h}$.

\begin{tabular}{ccc}
\hline Relative Humidity (\%) & Moisture Loss (g) Wet Test & Moisture Gain (g) Dry Test \\
\hline $35 \%$ & 15.8 & 9.75 \\
$50 \%$ & 16.21 & 13.6 \\
$65 \%$ & 9.08 & 21.9 \\
$80 \%$ & 3.65 & 28.53 \\
\hline
\end{tabular}

Table 6. Moisture measurement for Sample B $48 \mathrm{~h}$.

\begin{tabular}{ccc}
\hline Relative Humidity (\%) & Moisture Loss (g) Wet Test & Moisture Gain (g) Dry Test \\
\hline $35 \%$ & 5.5 & 4.01 \\
$50 \%$ & 6.0 & 4.1 \\
$65 \%$ & 3.95 & 7.22 \\
$80 \%$ & 1.61 & 9.33 \\
\hline
\end{tabular}

Tables A1-A4 in the Appendix A show the measured mass and calculated water vapour resistivity properties of specimen $\mathrm{A}$ at $23{ }^{\circ} \mathrm{C}$ and $35 \% \mathrm{RH}, 50 \% \mathrm{RH}, 65 \% \mathrm{RH}$ and $80 \%$ RH. Tables A5-A8 in the Appendix A show the measured mass and calculated water vapour resistivity properties of specimen $\mathrm{B}$ at $23{ }^{\circ} \mathrm{C}$ and $35 \% \mathrm{RH}, 50 \% \mathrm{RH}, 65 \% \mathrm{RH}$ and $80 \%$ RH. Table 7 , below, shows the summary of the calculated results for the water vapour 
resistance factor $\mu$ and the diffusion equivalent air layer thickness for the two pliable building membranes that were tested via the dry cup and wet cup methods.

Table 7. Summary of resistance factor $\mu$ and diffusion air layer thickness Sd.

\begin{tabular}{ccccc}
\hline $\mathbf{R H} \%$ & $\begin{array}{c}\text { Dry Test Resistance } \\
\text { Factor } \boldsymbol{\mu}\end{array}$ & $\begin{array}{c}\text { Wet Test Resistance } \\
\text { Factor } \boldsymbol{\mu}\end{array}$ & Dry Test Sd (m) & Wet Test Sd (m) \\
\hline & & Sample A & & \\
35 & 88.88 & 95.8 & 0.0724 & 0.078 \\
50 & 96.01 & 64.04 & 0.0772 & 0.052 \\
65 & 69.05 & 78.11 & 0.0551 & 0.062 \\
80 & 66.17 & 90.37 & 0.051 & 0.073 \\
& & Sample B & & \\
35 & 457 & 490.83 & 0.2113 & 0.2248 \\
50 & 599.6 & 365.9 & 0.2842 & 0.1744 \\
80 & 448.2 & 375.9 & 0.2128 & 0.1616 \\
\hline
\end{tabular}

\section{Discussion}

For many years, the standard experimental method to characterize a material's vapour resistivity properties has relied on the test methods described within ASTM E96m and ISO 12572. These standards and guidelines recommend a single temperature and relative humidity for carrying out this measurement, namely of $23{ }^{\circ} \mathrm{C}\left( \pm 5^{\circ} \mathrm{C}\right)$ and a relative humidity of $50 \%( \pm 5 \%)$. This research has been calling into question this simple single point test method.

Figure 16, below, shows the graphed moisture migration plotted against the varying relative humidity from $35 \%$ to $50 \%$ to $65 \%$ and $80 \%$ for pliable membrane material Sample A. Figure 17, below, shows the graphed moisture migration plotted against the varying relative humidity from $35 \%$ to $50 \%$ to $65 \%$ and $80 \%$ for pliable membrane material B.

Both materials show a difference in water vapour diffusion for different relative humidity values. During the dry cup tests, both pliable membrane materials had increased amounts of mass for each increase in relative humidity, indicating a greater amount of water vapour diffusion. During the wet cup tests, both pliable membrane materials had decreased amounts of mass for each increase in relative humidity, indicating a lesser amount of water vapour diffusion. The graphs indicate that there is not a straight linear relationship between rates of water vapour diffusion relative to relative humidity. Rather, the graphs show that the rates of water vapour diffusion significantly change when the test room was conditioned to $65 \% \mathrm{RH}$ and $80 \% \mathrm{RH}$. These measurements indicate that the vapour diffusion properties of the tested pliable membrane materials change subject to the relative humidity that they are experiencing. By implication, depending on the vapour pressure, a material will diffuse water vapour at different rates, depending on the relative humidity of the surrounding environment. Additionally, the results show that the rate of moisture diffusion for the wet cup tests and the dry cup tests demonstrate an inverse relationship subject to relative humidity. The graphs show that materials measured by the dry cup test method are more open to water vapour diffusion at higher relative humidity than the wet cup test method. This would indicate that the type of test method chosen by a product manufacturer could provide a skewed result for the product vapour diffusion properties. 


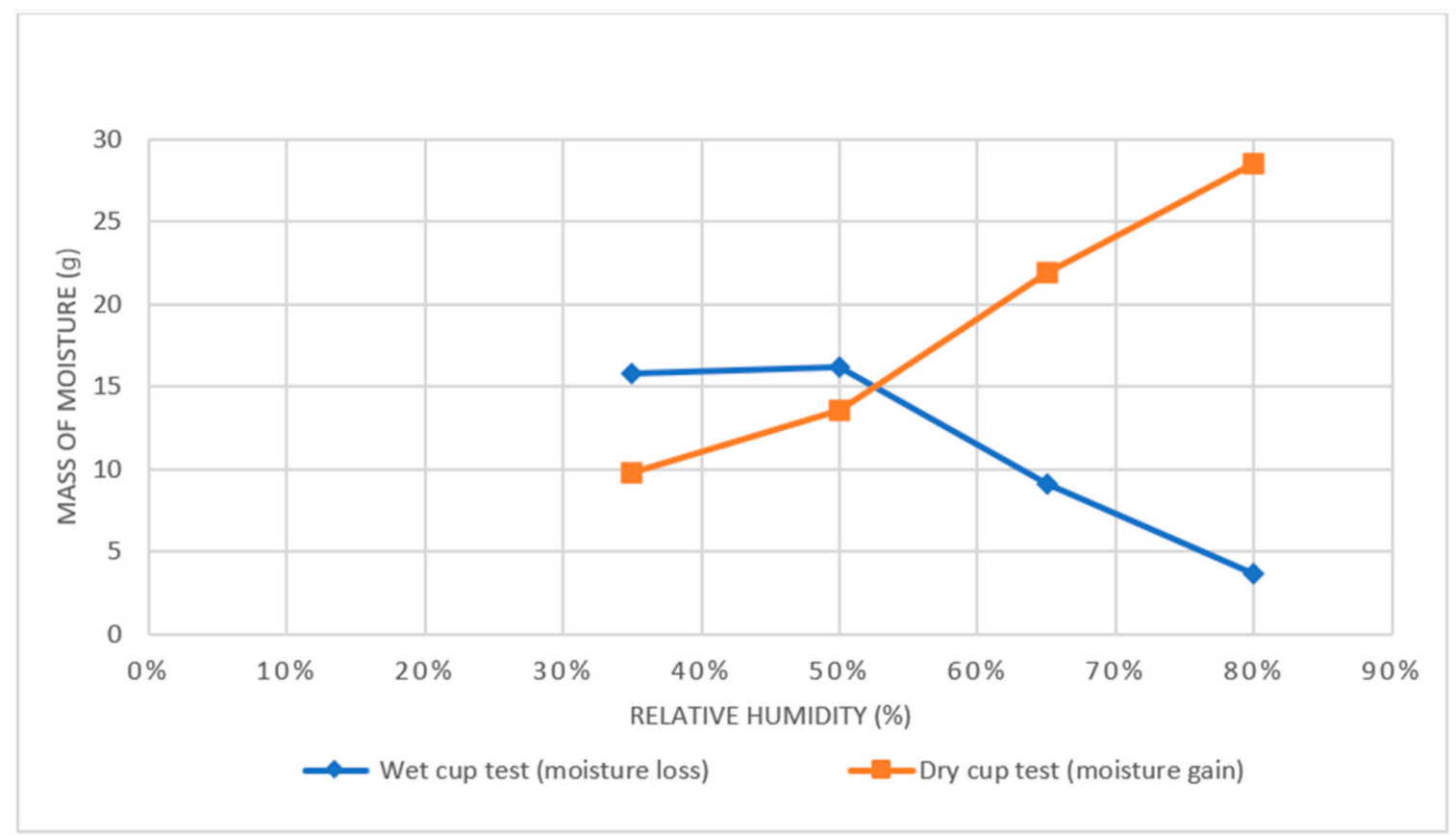

Figure 16. Graph showing the transfer of moisture in varying relative humidity for Sample A.

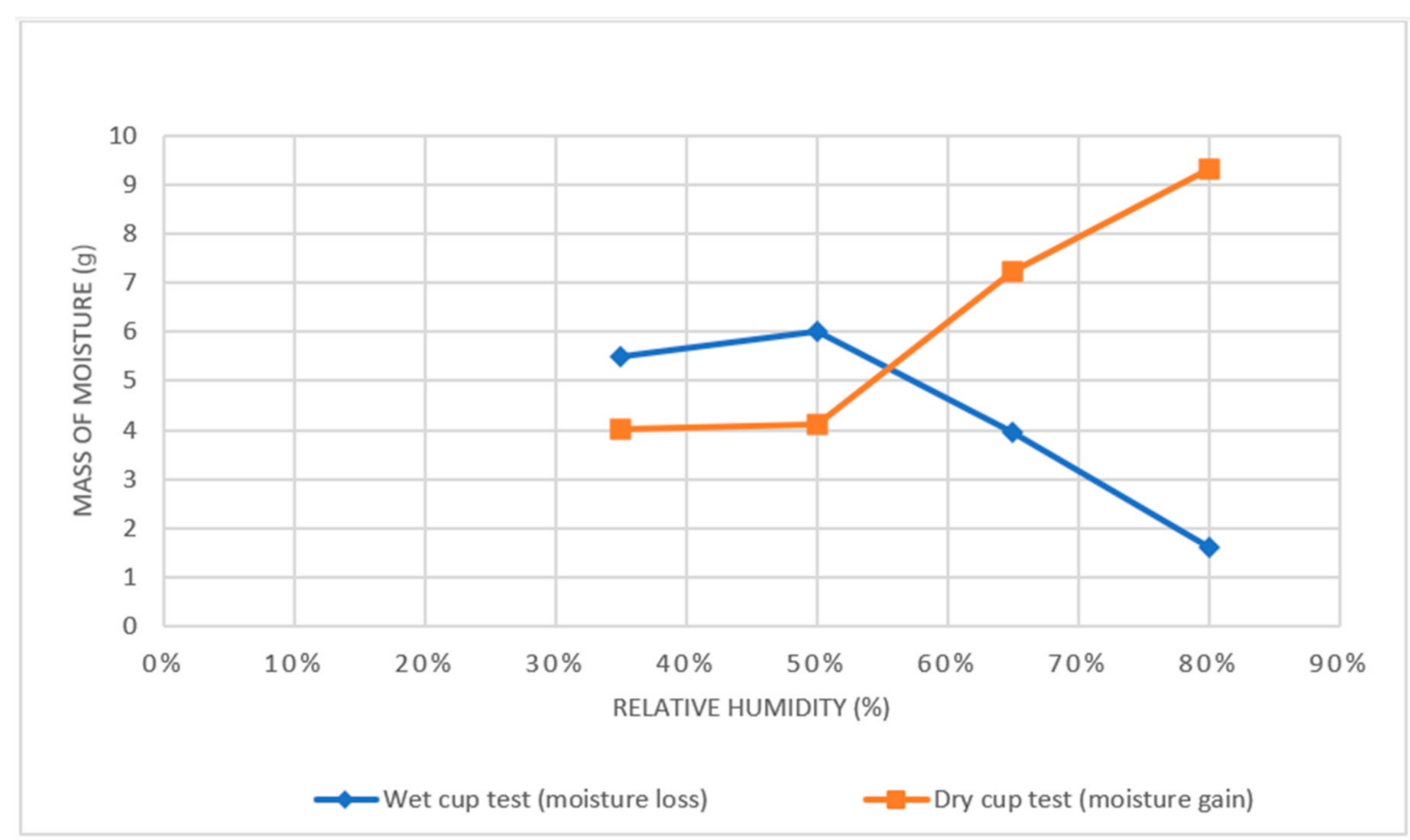

Figure 17. Graph showing the transfer of moisture in varying relative humidity for Sample B.

Figures 18 and 19, below, show the water vapour resistance factor and the diffusion equivalent air layer thickness plotted against varying relative humidity for material Sample A. Similarly, Figures 20 and 21, below, show the plot of the varying relative humidity against the water vapour resistance factor and the diffusion equivalent air layer thickness for material Sample B. Each of these graphs show differences in water vapour diffusion properties, subject to the relative humidity condition in the room. 


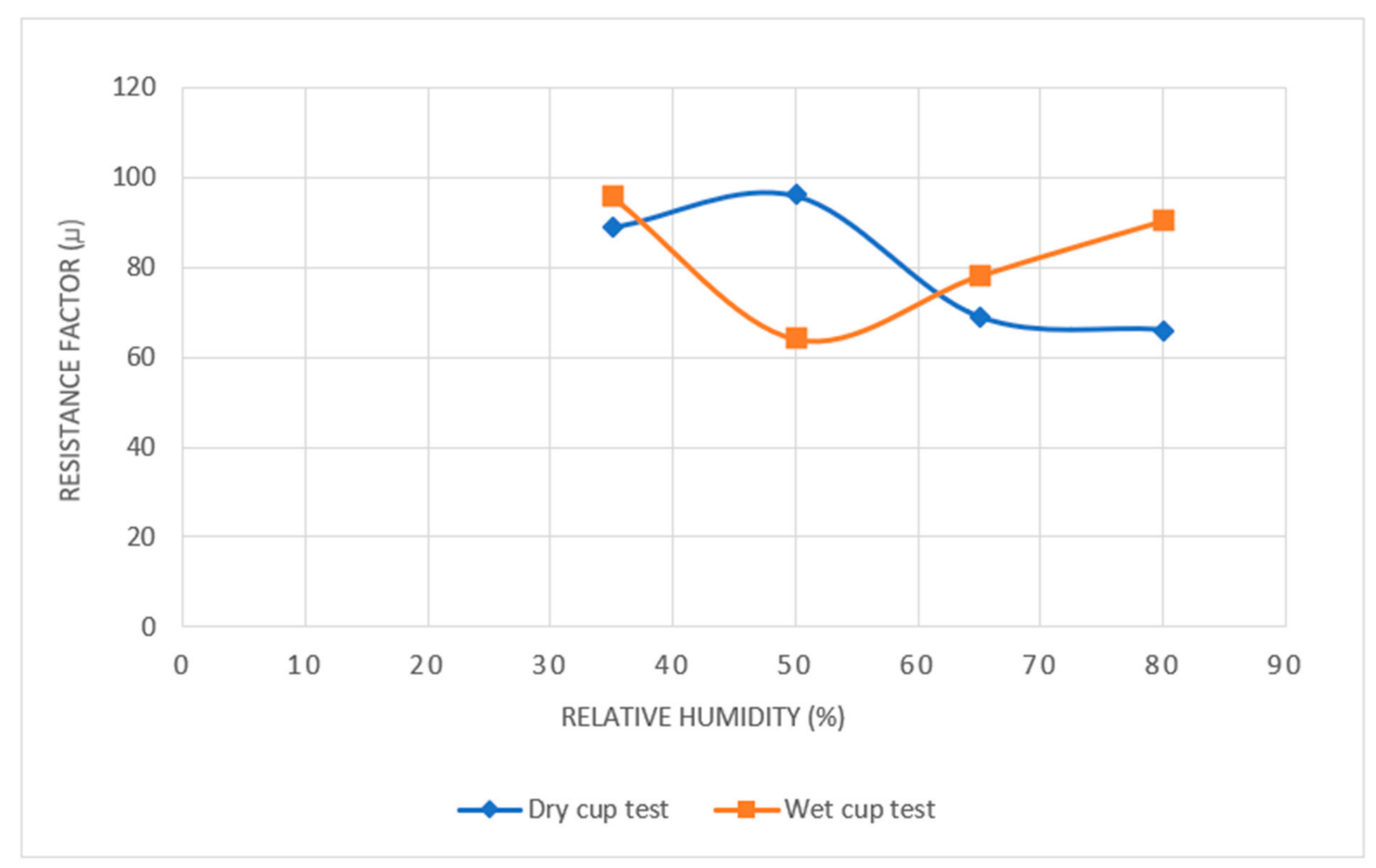

Figure 18. The graph showing the dynamic characteristics of the resistance factor of Sample A.

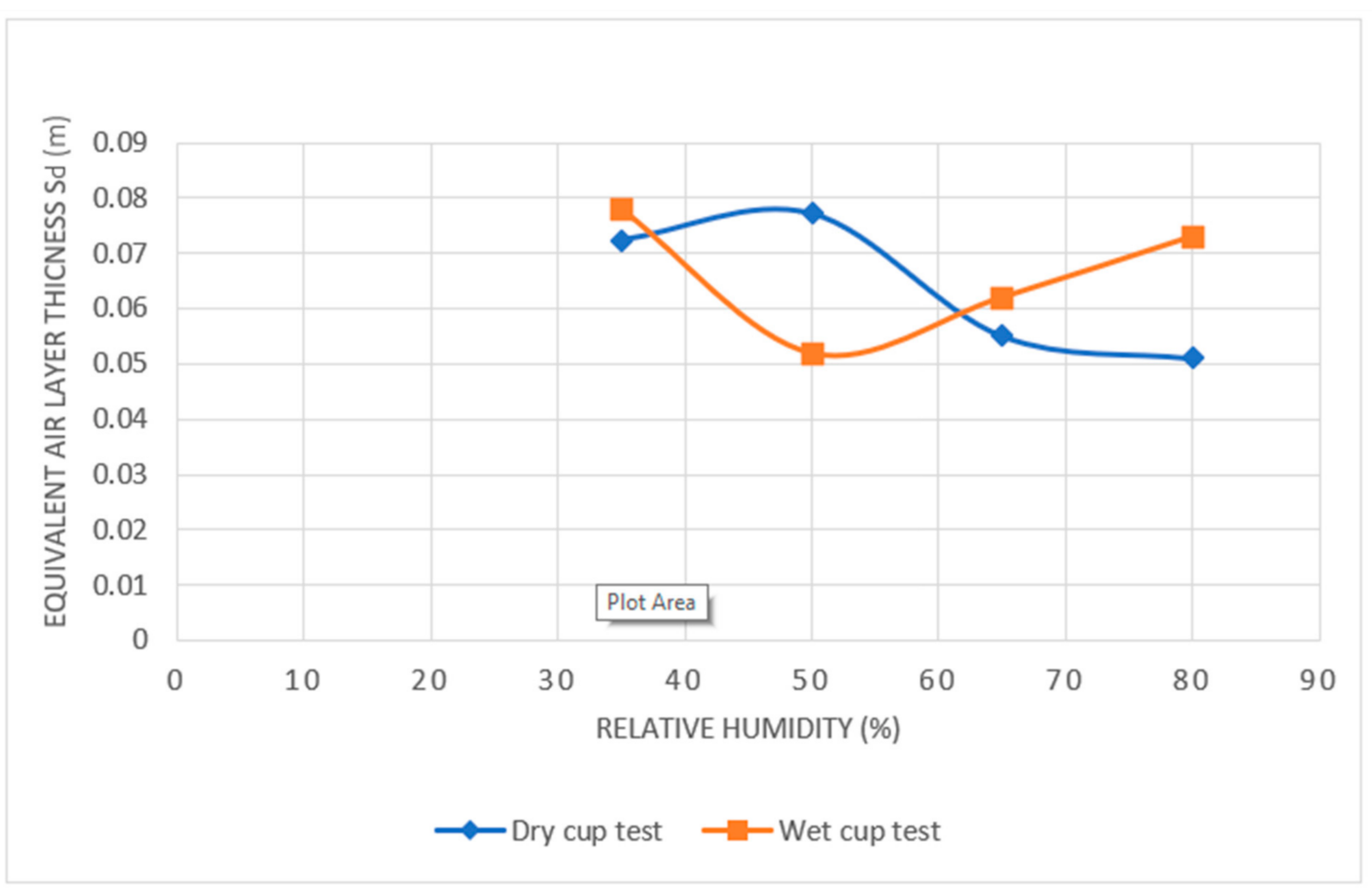

Figure 19. The graph showing the dynamic characteristics of the equivalent diffusion air layer thickness for Sample A. 


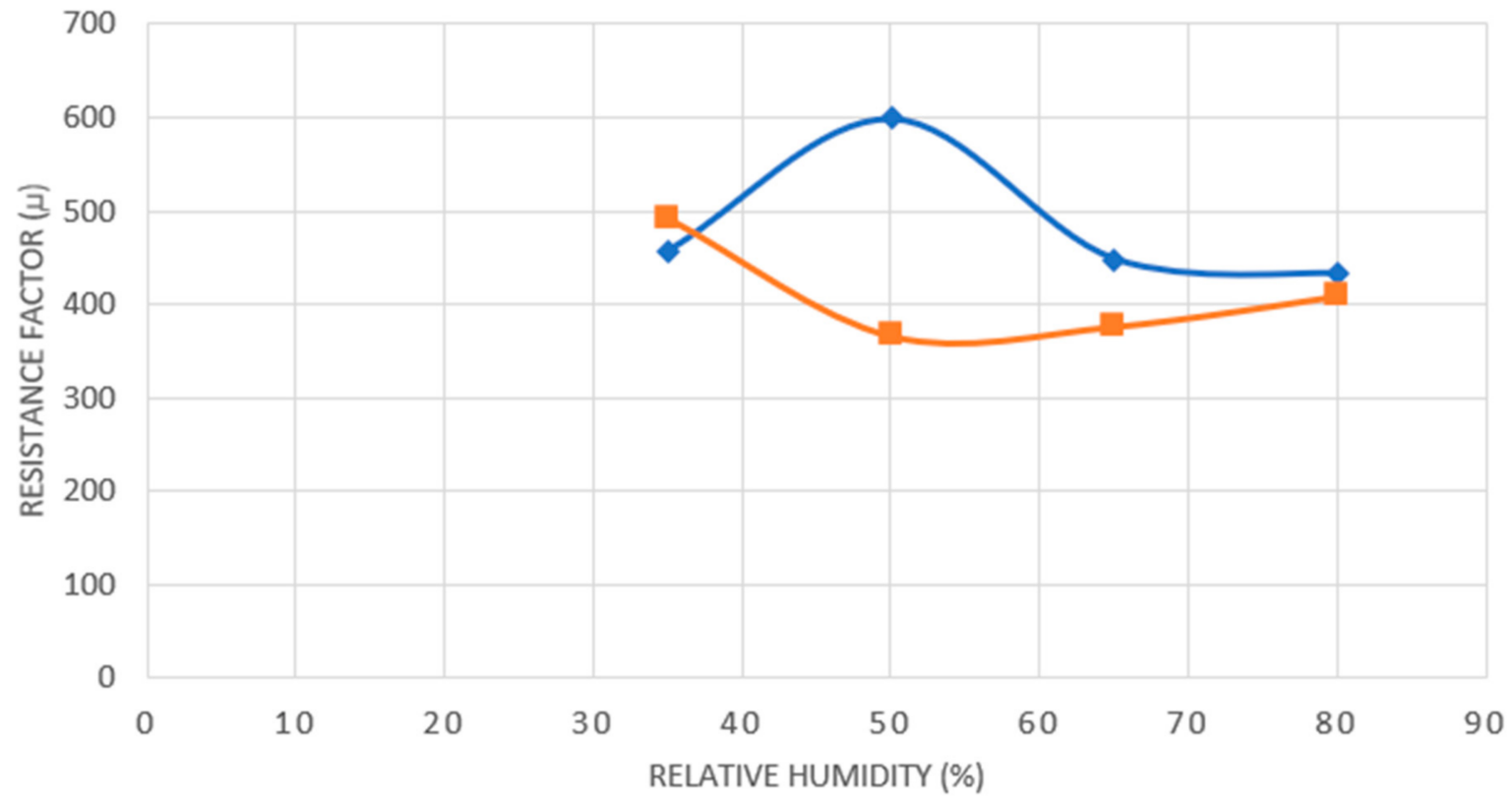

$\longrightarrow$ Dry cup test $\quad \longrightarrow$ Wet cup test

Figure 20. The graph showing the dynamic characteristics of the resistance factor of Sample B.

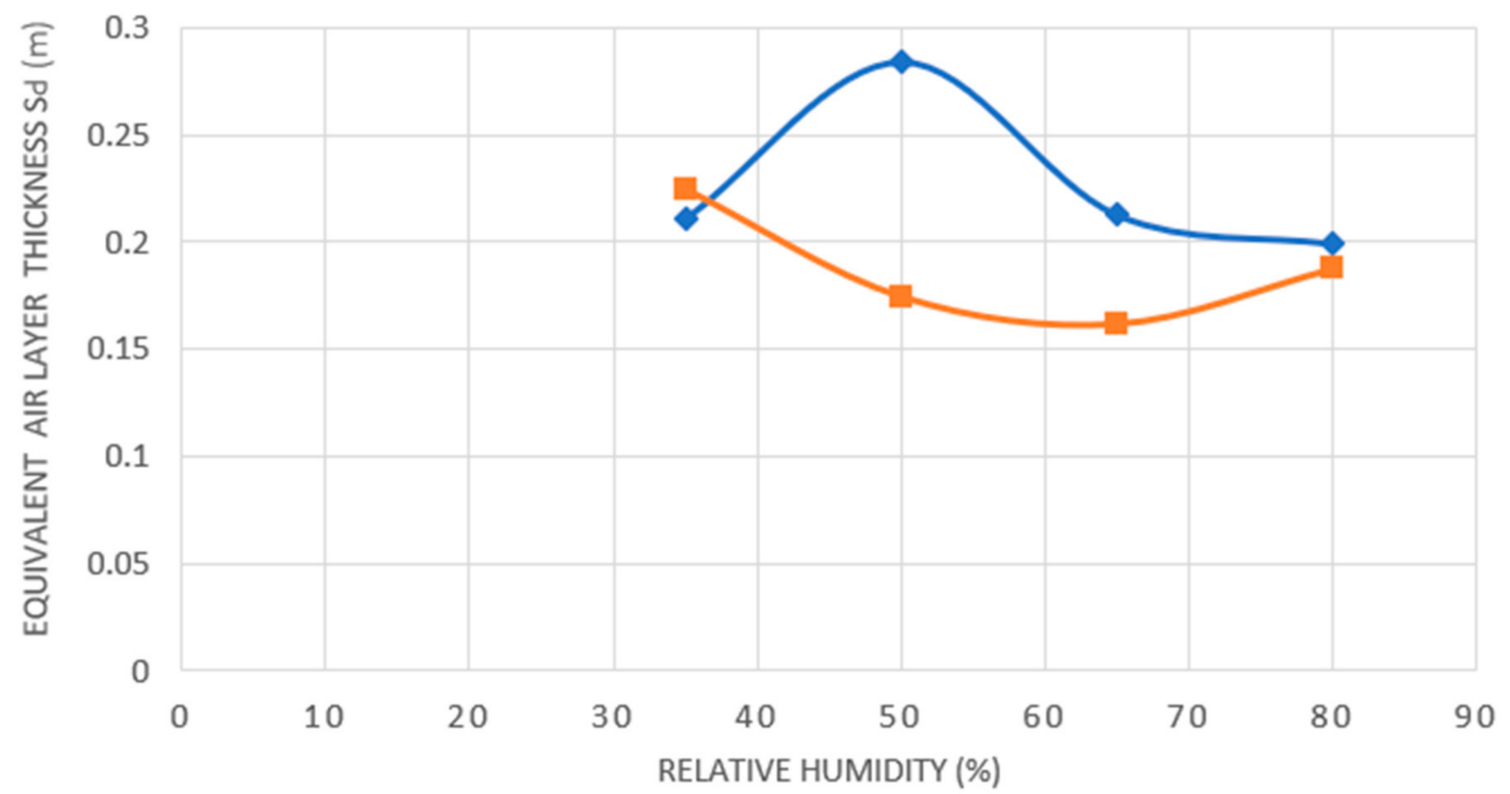

$\longrightarrow$ Dry cup test $\quad-$ Wet cup test

Figure 21. The graph showing the dynamic characteristics of the equivalent diffusion air layer thickness for Sample B. 
These results and analysis indicate a dynamic behavioural response subject to the relative humidity, which is not recognised by the material testing methods prescribed by the ASTM E96 M and ISO 12572. In this experiment, the two materials tested were pliable building membranes, which play a pivotal role in the management of water vapour diffusion within the external envelope. In this experiment, these two vapour-permeable membranes diffused water vapour in a different manner:

A material with temperature- and relative humidity-dependent static vapour diffusion properties may exhibit a linear characteristic to relative humidity, while a material with temperature- and relative humidity-dependent, non-static (dynamic) vapour diffusion properties would demonstrate a non-linear characteristic. The effect on the vapour diffusion properties for the two tested pliable building membrane products demonstrates significant dynamic behaviours subject to the relative humidity they are experiencing, as demonstrated by the changes in test dish mass and the calculated and graphed values for the air layer thickness and the vapour resistance factors. The air layer thickness and vapour resistance factors are crucially important input variables for a hygrothermal simulation. Therefore, for the two permeable pliable building membranes that were tested in this research, the current single point (static) method may provide incorrect simulation results due to the non-static (dynamic) relationship measured in this research.

\section{Conclusions}

The aim of this research was to establish if the water vapour diffusion properties of construction materials is variable or fixed, subject to the relative humidity conditions they experience. This line of enquiry has been developed in response to concern about the static nature of the standard test methods to establish water vapour diffusion properties of construction materials. The standard test method recommends a single point of measurement, where the test room has a temperature of $23{ }^{\circ} \mathrm{C}\left( \pm 5^{\circ} \mathrm{C}\right)$ and a relative humidity of $50 \%$ $( \pm-5 \%)$. It has been identified that this method may not provide inadequate information about the vapour diffusion properties of construction materials, which experience continuously varying temperature and relative humidity conditions on and within the external envelope of buildings.

In this research, two vapour-permeable materials were tested within an environmentally controlled test room with a constant temperature of $23{ }^{\circ} \mathrm{C}$ and four separate material testing periods where the relative humidity value was maintained at $36 \%, 50.4 \%, 65.12 \%$ and $80.29 \%$. The results for the test room environmental conditions demonstrated that the room was maintained within acceptable limits of $\pm 1{ }^{\circ} \mathrm{C}$ and $\pm 2.5 \% \mathrm{RH}$ for all four material testing periods. The results showed different water vapour diffusion properties for both pliable membrane materials (A and B) subject to the relative humidity conditions. Additionally, the results from the measurement and calculation of vapour diffusion properties indicate that the tested materials behave differently when subjected to the wet cup or dry cup test. The graphed results for both materials diffusion resistance factor and equivalent layer thickness against the varying relative humidity demonstrated a dynamic and inverse behaviour.

These findings indicate that the current single point test method referenced in AS4200.1, which refers to ISO:12572 and ASTM: E96M, may be inappropriate for providing high quality water vapour diffusion material properties for hygrothermally simulating the external envelope of buildings. The external envelope of buildings the world over continuously experiences dynamic temperature and humidity conditions. This research has demonstrated that, for the two materials reported here, the vapour diffusion properties change subject to relative humidity conditions.

Finally, further research is needed to investigate the impact of the varying relative humidity on other construction materials, as well as the impact of varying temperature on these permeable materials and other construction materials. 
Author Contributions: T.S.O.-Main author carried out the all the experiments at UTAS, involved in the conceptualization; collected data; analysed data; contributed to graphs and visualization; provided the original draft manuscript and revised manuscript. M.D.-Second author provided guidance to experiment; sourced for funding to procure equipment and project administration; contributed to data analysis and data curation; contributed to graphs and visualization; edited and provided revision to the manuscript. H.K.-Provided guidance for the laboratory operation, supervision, and revision of manuscript. All authors have read and agreed to the published version of the manuscript.

Funding: This research was co-funded by Commonwealth Scientific Industrial Research Organization (CSIRO), grant number 00004612.

Institutional Review Board Statement: Not applicable.

Informed Consent Statement: Not applicable.

Acknowledgments: These authors acknowledge Des FitzGerald, the University of Tasmania, for providing mathematical and statistical support in this research.

Conflicts of Interest: The authors declare no conflict of interest.

\section{Appendix A}

Table A1. Water vapour resistivity properties for sample A @35\%RH $23{ }^{\circ} \mathrm{C}$.

\begin{tabular}{|c|c|c|c|c|c|c|c|c|c|}
\hline $\begin{array}{l}\text { Sample } \\
@ 23{ }^{\circ} \mathrm{C} \\
35 \% \mathrm{RH}\end{array}$ & $\begin{array}{c}\text { Mean } \\
\text { Thickness } \\
\text { d (m) }\end{array}$ & $\begin{array}{l}\text { Mass } \\
\text { Change } \\
\text { Rate/Time } \\
\text { (G in kg/s) }\end{array}$ & $\underset{\mathbf{m}^{2}}{\text { Area }}$ & $\begin{array}{c}\text { Water } \\
\text { Vapour Flux } \\
\mathrm{g}=\mathrm{G} / \mathrm{A} \text { in } \\
\mathrm{kg} /\left(\mathrm{s} \times \mathrm{m}^{\mathbf{2}}\right)\end{array}$ & $\begin{array}{l}\text { Water Vapour } \\
\text { Permeance } \\
\text { W=g/dp in } \mathrm{kg} / \\
\left(\mathrm{s} \times \mathrm{m}^{2} \times \mathrm{Pa}\right)\end{array}$ & $\begin{array}{c}\text { Water Vapour } \\
\text { Resistance } \\
\mathrm{Z}=1 / \mathrm{W} \text { in } \\
\left(\mathrm{s} \times \mathrm{m}^{2} \times \mathrm{Pa}\right) / \mathrm{kg}\end{array}$ & $\begin{array}{c}\text { Water Vapour } \\
\text { Permeability } \\
\delta=W \times d \text { in } \\
\mathrm{kg} /(\mathrm{s} \times \mathbf{m} \times \mathbf{P a})\end{array}$ & $\begin{array}{c}\text { Water } \\
\text { Vapour } \\
\text { Resistance } \\
\text { Factor } \mu\end{array}$ & $\begin{array}{c}\text { Diffusion- } \\
\text { Equivalent } \\
\text { Air Layer } \\
\text { Thickness } \\
\text { Sd }\end{array}$ \\
\hline & & & & & Dry cup test & & & & \\
\hline A-1 & 0.000818 & $4.8 \times 10^{-8}$ & 0.02745 & $1.7 \times 10^{-6}$ & $1.9 \times 10^{-9}$ & $5.2 \times 10^{8}$ & $1.6 \times 10^{-12}$ & 99.5800 & 0.0815 \\
\hline A-2 & 0.000832 & $5.3 \times 10^{-8}$ & 0.02690 & $2.0 \times 10^{-6}$ & $2.2 \times 10^{-9}$ & $4.6 \times 10^{8}$ & $1.8 \times 10^{-12}$ & 83.2100 & 0.0692 \\
\hline A-3 & 0.000806 & $5.4 \times 10^{-8}$ & 0.02690 & $2.0 \times 10^{-6}$ & $2.2 \times 10^{-9}$ & $4.5 \times 10^{8}$ & $1.8 \times 10^{-12}$ & 84.3770 & 0.0680 \\
\hline A-4 & 0.000813 & $5.2 \times 10^{-8}$ & 0.02690 & $1.9 \times 10^{-6}$ & $2.1 \times 10^{-9}$ & $4.7 \times 10^{8}$ & $1.7 \times 10^{-12}$ & 88.0300 & 0.0716 \\
\hline A-5 & 0.000804 & $5.1 \times 10^{-8}$ & 0.02660 & $1.9 \times 10^{-6}$ & $2.1 \times 10^{-9}$ & $4.7 \times 10^{8}$ & $1.7 \times 10^{-12}$ & 89.2200 & 0.0717 \\
\hline Mean & 0.000815 & $5.1 \times 10^{-8}$ & 0.02695 & $1.9 \times 10^{-6}$ & $\begin{array}{c}2.1 \times 10^{-9} \\
\text { Wet cup test }\end{array}$ & $4.7 \times 10^{8}$ & $1.7 \times 10^{-12}$ & 88.8834 & 0.0724 \\
\hline A-6 & 0.000825 & $7.5 \times 10^{-8}$ & 0.02690 & $2.8 \times 10^{-6}$ & $1.7 \times 10^{-9}$ & $5.8 \times 10^{8}$ & $1.4 \times 10^{-12}$ & 113.9300 & 0.0939 \\
\hline A-7 & 0.000825 & $1.0 \times 10^{-7}$ & 0.02660 & $3.8 \times 10^{-6}$ & $2.4 \times 10^{-9}$ & $4.2 \times 10^{8}$ & $1.9 \times 10^{-12}$ & 76.4600 & 0.0631 \\
\hline A-8 & 0.000804 & $9.0 \times 10^{-8}$ & 0.02630 & $3.4 \times 10^{-6}$ & $2.1 \times 10^{-9}$ & $4.8 \times 10^{8}$ & $1.7 \times 10^{-12}$ & 91.8400 & 0.0735 \\
\hline A-9 & 0.000824 & $9.8 \times 10^{-8}$ & 0.02745 & $3.6 \times 10^{-6}$ & $2.2 \times 10^{-9}$ & $4.5 \times 10^{8}$ & $1.8 \times 10^{-12}$ & 83.6100 & 0.0689 \\
\hline A-10 & 0.000801 & $8.2 \times 10^{-8}$ & 0.02834 & $2.9 \times 10^{-6}$ & $1.8 \times 10^{-9}$ & $5.7 \times 10^{8}$ & $1.4 \times 10^{-12}$ & 113.1600 & 0.0906 \\
\hline Mean & 0.000816 & $8.9 \times 10^{-8}$ & 0.02712 & $3.3 \times 10^{-6}$ & $2.0 \times 10^{-9}$ & $5.0 \times 10^{8}$ & $1.7 \times 10^{-12}$ & 95.8000 & 0.0780 \\
\hline
\end{tabular}

Table A2. Water vapour resistivity properties of sample A @23 ${ }^{\circ} \mathrm{C} 50 \% \mathrm{RH}$.

\begin{tabular}{|c|c|c|c|c|c|c|c|c|c|}
\hline $\begin{array}{l}\text { Sample } \\
\text { Tested } \\
@ 23{ }^{\circ} \mathrm{C} \\
50 \% \mathrm{RH}\end{array}$ & $\begin{array}{l}\text { Mean } \\
\text { Thickness } \\
\text { d (m) }\end{array}$ & $\begin{array}{c}\text { Mass } \\
\text { Change } \\
\text { Rate/Time } \\
\text { (G in kg/s) }\end{array}$ & $\underset{\mathrm{m}^{2}}{\operatorname{Area}}$ & $\begin{array}{c}\text { Water } \\
\text { Vapour Flux } \\
\mathrm{g}=\mathrm{G} / \mathrm{A} \text { in } \\
\mathrm{kg} /\left(\mathrm{s} \times \mathrm{m}^{\mathbf{2}}\right)\end{array}$ & $\begin{array}{l}\text { Water Vapour } \\
\text { Permeance } \\
\mathbf{W}=\mathrm{g} / \mathrm{dp} \text { in } \mathrm{kg} / \\
\left(\mathrm{s} \times \mathrm{m}^{2} \times \mathrm{Pa}\right)\end{array}$ & $\begin{array}{c}\text { Water Vapour } \\
\text { Resistance } \\
\mathrm{Z}=1 / \mathrm{W} \text { in } \\
\left(\mathrm{s} \times \mathrm{m}^{2} \times \mathrm{Pa}\right) / \mathrm{kg}\end{array}$ & $\begin{array}{c}\text { Water Vapour } \\
\text { Permeability } \\
\delta=W \times d \text { in } \\
\mathrm{kg} /(\mathbf{s} \times \mathbf{m} \times \mathbf{P a})\end{array}$ & $\begin{array}{c}\text { Water } \\
\text { Vapour } \\
\text { Resistance } \\
\text { Factor } \mu\end{array}$ & $\begin{array}{c}\text { Diffusion- } \\
\text { Equivalent } \\
\text { Air Layer } \\
\text { Thickness } \\
\text { Sd }\end{array}$ \\
\hline & & & & & Dry cup test & & & & \\
\hline A-1 & 0.000804 & $5.7 \times 10^{-8}$ & 0.02775 & $2.1 \times 10^{-6}$ & $1.6 \times 10^{-9}$ & $6.4 \times 10^{8}$ & $1.3 \times 10^{-12}$ & 128.3300 & 0.1032 \\
\hline A-2 & 0.000819 & $8.5 \times 10^{-8}$ & 0.02750 & $3.1 \times 10^{-6}$ & $2.3 \times 10^{-9}$ & $4.3 \times 10^{8}$ & $1.9 \times 10^{-12}$ & 76.0200 & 0.0623 \\
\hline A-3 & 0.000794 & $8.1 \times 10^{-8}$ & 0.02660 & $3.0 \times 10^{-6}$ & $2.3 \times 10^{-9}$ & $4.4 \times 10^{8}$ & $1.8 \times 10^{-12}$ & 80.0900 & 0.0636 \\
\hline A-4 & 0.000784 & $1.0 \times 10^{-7}$ & 0.02600 & $4.0 \times 10^{-6}$ & $3.0 \times 10^{-9}$ & $3.3 \times 10^{8}$ & $2.4 \times 10^{-12}$ & 55.7600 & 0.0437 \\
\hline A-5 & 0.000808 & $5.2 \times 10^{-8}$ & 0.02750 & $1.9 \times 10^{-6}$ & $1.4 \times 10^{-9}$ & $6.9 \times 10^{8}$ & $1.2 \times 10^{-12}$ & 139.8500 & 0.1131 \\
\hline Mean & 0.000802 & $7.6 \times 10^{-8}$ & 0.02707 & $2.8 \times 10^{-6}$ & $\begin{array}{c}2.1 \times 10^{-9} \\
\text { Wet cup test }\end{array}$ & $5.1 \times 10^{8}$ & $1.7 \times 10^{-12}$ & 96.0100 & 0.0772 \\
\hline A-6 & 0.000836 & $7.4 \times 10^{-8}$ & 0.02775 & $2.3 \times 10^{-6}$ & $2.2 \times 10^{-9}$ & $4.5 \times 10^{8}$ & $1.8 \times 10^{-12}$ & 85.3400 & 0.0680 \\
\hline A-7 & 0.000824 & $9.2 \times 10^{-8}$ & 0.02750 & $3.3 \times 10^{-6}$ & $2.8 \times 10^{-9}$ & $3.6 \times 10^{8}$ & $2.8 \times 10^{-12}$ & 60.9900 & 0.0503 \\
\hline A-8 & 0.000808 & $1.0 \times 10^{-7}$ & 0.02775 & $3.6 \times 10^{-6}$ & $3.0 \times 10^{-9}$ & $3.4 \times 10^{8}$ & $2.4 \times 10^{-12}$ & 55.9800 & 0.0452 \\
\hline A-9 & 0.000804 & $9.9 \times 10^{-8}$ & 0.02775 & $3.6 \times 10^{-6}$ & $2.9 \times 10^{-9}$ & $3.4 \times 10^{8}$ & $2.4 \times 10^{-12}$ & 57.1540 & 0.0459 \\
\hline A-10 & 0.000805 & $9.3 \times 10^{-8}$ & 0.02745 & $3.4 \times 10^{-6}$ & $2.8 \times 10^{-9}$ & $3.6 \times 10^{8}$ & $2.3 \times 10^{-12}$ & 60.8100 & 0.0490 \\
\hline Mean & 0.000815 & $9.1 \times 10^{-8}$ & 0.02764 & $3.2 \times 10^{-6}$ & $2.7 \times 10^{-9}$ & $3.7 \times 10^{8}$ & $2.3 \times 10^{-12}$ & 64.0548 & 0.0517 \\
\hline
\end{tabular}


Table A3. Water vapour resistivity properties of sample A @ $23{ }^{\circ} \mathrm{C} 65 \% \mathrm{RH}$.

\begin{tabular}{|c|c|c|c|c|c|c|c|c|c|}
\hline $\begin{array}{l}\text { Sample } \\
\text { Tested } \\
@ 23{ }^{\circ} \mathrm{C} \\
65 \% \mathrm{RH}\end{array}$ & $\begin{array}{c}\text { Mean } \\
\text { Thickness } \\
\text { d (m) }\end{array}$ & $\begin{array}{l}\text { Mass } \\
\text { Change } \\
\text { Rate/Time } \\
\text { (G in kg/s) }\end{array}$ & $\underset{\mathbf{m}^{2}}{\operatorname{Area}}$ & $\begin{array}{c}\text { Water } \\
\text { Vapour Flux } \\
\mathrm{g}=\mathrm{G} / \mathrm{A} \text { in } \\
\mathrm{kg} /\left(\mathrm{s} \times \mathrm{m}^{2}\right)\end{array}$ & $\begin{array}{l}\text { Water Vapour } \\
\text { Permeance } \\
\mathrm{W}=\mathrm{g} / \mathrm{dp} \text { in } \mathrm{kg} / \\
\left(\mathrm{s} \times \mathrm{m}^{2} \times \mathrm{Pa}\right)\end{array}$ & $\begin{array}{c}\text { Water Vapour } \\
\text { Resistance } \\
\mathrm{Z}=1 / \mathrm{W} \text { in } \\
\left(\mathrm{s} \times \mathrm{m}^{2} \times \mathrm{Pa}\right) / \mathrm{kg}\end{array}$ & $\begin{array}{c}\text { Water Vapour } \\
\text { Permeability } \\
\delta=W \times d \text { in } \\
\mathrm{kg} /(\mathbf{s} \times \mathbf{m} \times \mathbf{P a})\end{array}$ & $\begin{array}{c}\text { Water } \\
\text { Vapour } \\
\text { Resistance } \\
\text { Factor } \mu\end{array}$ & $\begin{array}{c}\text { Diffusion- } \\
\text { Equivalent } \\
\text { Air Layer } \\
\text { Thickness } \\
\text { Sd }\end{array}$ \\
\hline A-1 & 0.000819 & $1.4 \times 10^{-7}$ & 0.02778 & $5.0 \times 10^{-6}$ & $\begin{array}{c}\text { Dry cup test } \\
2.9 \times 10^{-9}\end{array}$ & $3.5 \times 10^{8}$ & $2.4 \times 10^{-12}$ & 57.7200 & 0.0473 \\
\hline A-2 & 0.000795 & $1.4 \times 10^{-7}$ & 0.02750 & $4.9 \times 10^{-6}$ & $2.8 \times 10^{-9}$ & $3.5 \times 10^{8}$ & $2.3 \times 10^{-12}$ & 61.3300 & 0.0488 \\
\hline A- 3 & 0.000793 & $1.0 \times 10^{-7}$ & 0.02750 & $3.8 \times 10^{-6}$ & $2.2 \times 10^{-9}$ & $4.6 \times 10^{8}$ & $1.7 \times 10^{-12}$ & 87.6300 & 0.0695 \\
\hline A- 4 & 0.000795 & $1.4 \times 10^{-7}$ & 0.02750 & $5.0 \times 10^{-6}$ & $2.9 \times 10^{-9}$ & $3.5 \times 10^{8}$ & $2.3 \times 10^{-12}$ & 58.3500 & 0.0464 \\
\hline A- 5 & 0.000790 & $1.1 \times 10^{-7}$ & 0.02720 & $4.1 \times 10^{-6}$ & $2.3 \times 10^{-9}$ & $4.3 \times 10^{8}$ & $1.8 \times 10^{-12}$ & 80.2200 & 0.0634 \\
\hline Mean & 0.000798 & $1.3 \times 10^{-7}$ & 0.02750 & $4.6 \times 10^{-6}$ & $\begin{array}{c}2.6 \times 10^{-9} \\
\text { Wet cup test }\end{array}$ & $3.9 \times 10^{8}$ & $2.1 \times 10^{-12}$ & 69.0500 & 0.0551 \\
\hline A-6 & 0.000772 & $5.5 \times 10^{-8}$ & 0.02750 & $2.0 \times 10^{-6}$ & $2.5 \times 10^{-9}$ & $3.9 \times 10^{8}$ & $2.0 \times 10^{-12}$ & 73.9300 & 0.0571 \\
\hline A-7 & 0.000798 & $5.2 \times 10^{-8}$ & 0.02630 & $2.0 \times 10^{-6}$ & $2.5 \times 10^{-9}$ & $3.9 \times 10^{8}$ & $2.1 \times 10^{-12}$ & 70.3900 & 0.0562 \\
\hline A-8 & 0.000814 & $4.3 \times 10^{-8}$ & 0.02780 & $1.5 \times 10^{-6}$ & $2.0 \times 10^{-9}$ & $5.1 \times 10^{8}$ & $1.6 \times 10^{-12}$ & 98.7200 & 0.0804 \\
\hline A-9 & 0.000793 & $4.9 \times 10^{-8}$ & 0.02750 & $1.8 \times 10^{-6}$ & $2.3 \times 10^{-9}$ & $4.4 \times 10^{8}$ & $1.8 \times 10^{-12}$ & 83.4000 & 0.0662 \\
\hline A-10 & 0.000791 & $6.1 \times 10^{-8}$ & 0.02780 & $2.2 \times 10^{-6}$ & $2.8 \times 10^{-9}$ & $3.6 \times 10^{8}$ & $2.2 \times 10^{-12}$ & 64.0990 & 0.0507 \\
\hline Mean & 0.000794 & $5.2 \times 10^{-8}$ & 0.02738 & $1.9 \times 10^{-6}$ & $2.4 \times 10^{-9}$ & $4.2 \times 10^{8}$ & $1.9 \times 10^{-12}$ & 78.1078 & 0.0621 \\
\hline
\end{tabular}

Table A4. Water vapour resistivity properties of sample A @23 ${ }^{\circ} \mathrm{C} 80 \% \mathrm{RH}$.

\begin{tabular}{|c|c|c|c|c|c|c|c|c|c|}
\hline $\begin{array}{l}\text { Sample } \\
\text { Tested } \\
@ 23^{\circ} \mathrm{C} \\
80 \% \mathrm{RH}\end{array}$ & $\begin{array}{c}\text { Mean } \\
\text { Thickness } \\
\text { d (m) }\end{array}$ & $\begin{array}{c}\text { Mass } \\
\text { Change } \\
\text { Rate/Time } \\
\text { (G in kg/s) }\end{array}$ & $\underset{\mathrm{m}^{2}}{\operatorname{Area}}$ & $\begin{array}{c}\text { Water } \\
\text { Vapour Flux } \\
\mathrm{g}=\mathrm{G} / \mathrm{A} \text { in } \\
\mathrm{kg} /\left(\mathrm{s} \times \mathrm{m}^{\mathbf{2}}\right)\end{array}$ & $\begin{array}{l}\text { Water Vapour } \\
\text { Permeance } \\
\mathrm{W}=\mathrm{g} / \mathrm{dp} \text { in } \mathrm{kg} / \\
\left(\mathrm{s} \times \mathrm{m}^{2} \times \mathrm{Pa}\right)\end{array}$ & $\begin{array}{c}\text { Water Vapour } \\
\text { Resistance } \\
\mathrm{Z}=1 / \mathrm{W} \text { in } \\
\left(\mathrm{s} \times \mathrm{m}^{2} \times \mathrm{Pa}\right) / \mathrm{kg}\end{array}$ & $\begin{array}{c}\text { Water Vapour } \\
\text { Permeability } \\
\delta=W \times \text { d in } \\
\mathrm{kg} /(\mathbf{s} \times \mathbf{m} \times \mathbf{P a})\end{array}$ & $\begin{array}{c}\text { Water } \\
\text { Vapour } \\
\text { Resistance } \\
\text { Factor } \mu\end{array}$ & $\begin{array}{c}\text { Diffusion- } \\
\text { Equivalent } \\
\text { Air Layer } \\
\text { Thickness } \\
\text { Sd }\end{array}$ \\
\hline & & & & & Dry cup test & & & & \\
\hline A-1 & 0.000774 & $1.4 \times 10^{-7}$ & 0.02780 & $4.7 \times 10^{-6}$ & $2.3 \times 10^{-9}$ & $4.4 \times 10^{8}$ & $1.8 \times 10^{-12}$ & 83.4000 & 0.0646 \\
\hline A-2 & 0.000765 & $1.7 \times 10^{-7}$ & 0.02720 & $6.1 \times 10^{-6}$ & $2.8 \times 10^{-9}$ & $3.5 \times 10^{8}$ & $2.2 \times 10^{-12}$ & 63.3200 & 0.0484 \\
\hline A-3 & 0.000773 & $1.6 \times 10^{-7}$ & 0.02720 & $5.9 \times 10^{-6}$ & $2.7 \times 10^{-9}$ & $3.7 \times 10^{8}$ & $2.1 \times 10^{-12}$ & 65.7200 & 0.0508 \\
\hline A-4 & 0.000764 & $1.8 \times 10^{-7}$ & 0.02780 & $6.4 \times 10^{-6}$ & $2.9 \times 10^{-9}$ & $3.4 \times 10^{8}$ & $2.2 \times 10^{-12}$ & 60.2000 & 0.0460 \\
\hline A-5 & 0.000775 & $1.8 \times 10^{-7}$ & 0.02750 & $6.4 \times 10^{-6}$ & $3.0 \times 10^{-9}$ & $3.4 \times 10^{8}$ & $2.3 \times 10^{-12}$ & 58.2000 & 0.0451 \\
\hline Mean & 0.000770 & $1.6 \times 10^{-7}$ & 0.02750 & $5.9 \times 10^{-6}$ & $\begin{array}{c}2.8 \times 10^{-9} \\
\text { Wet cup test }\end{array}$ & $3.7 \times 10^{8}$ & $2.1 \times 10^{-12}$ & 66.1680 & 0.0510 \\
\hline A-6 & 0.000835 & $2.0 \times 10^{-8}$ & 0.02780 & $7.0 \times 10^{-7}$ & $1.9 \times 10^{-9}$ & $5.2 \times 10^{8}$ & $1.6 \times 10^{-12}$ & 97.5100 & 0.0815 \\
\hline A-7 & 0.000829 & $2.1 \times 10^{-8}$ & 0.02810 & $7.5 \times 10^{-7}$ & $2.0 \times 10^{-9}$ & $4.9 \times 10^{8}$ & $1.7 \times 10^{-12}$ & 91.0000 & 0.0754 \\
\hline A-8 & 0.000807 & $1.8 \times 10^{-8}$ & 0.02750 & $6.6 \times 10^{-7}$ & $1.8 \times 10^{-9}$ & $5.6 \times 10^{8}$ & $1.5 \times 10^{-12}$ & 109.4600 & 0.0883 \\
\hline A-9 & 0.000833 & $2.3 \times 10^{-8}$ & 0.02780 & $8.2 \times 10^{-7}$ & $2.2 \times 10^{-9}$ & $4.5 \times 10^{8}$ & $1.9 \times 10^{-12}$ & 80.1300 & 0.0668 \\
\hline A-10 & 0.000823 & $2.4 \times 10^{-8}$ & 0.02750 & $8.8 \times 10^{-7}$ & $2.4 \times 10^{-9}$ & $4.1 \times 10^{8}$ & $2.0 \times 10^{-12}$ & 73.7500 & 0.0507 \\
\hline Mean & 0.000825 & $4.6 \times 10^{-7}$ & 0.02774 & $7.6 \times 10^{-7}$ & $2.1 \times 10^{-9}$ & $4.9 \times 10^{8}$ & $1.7 \times 10^{-12}$ & 90.3700 & 0.0725 \\
\hline
\end{tabular}

Table A5. Water vapour resistivity properties for sample B @23 ${ }^{\circ} \mathrm{C} 35 \% \mathrm{RH}$.

\begin{tabular}{|c|c|c|c|c|c|c|c|c|c|}
\hline $\begin{array}{c}\text { Sample } \\
\text { Tested } \\
@ 23{ }^{\circ} \mathrm{C} \\
35 \% \mathrm{RH}\end{array}$ & $\begin{array}{c}\text { Mean } \\
\text { Thickness } \\
\text { d (m) }\end{array}$ & $\begin{array}{l}\text { Mass } \\
\text { Change } \\
\text { Rate/Time } \\
\text { (G in kg/s) }\end{array}$ & $\underset{\mathbf{m}^{2}}{\text { Area }}$ & $\begin{array}{c}\text { Water } \\
\text { Vapour Flux } \\
\mathrm{g}=\mathrm{G} / \mathrm{A} \text { in } \\
\mathrm{kg} /\left(\mathrm{s} \times \mathrm{m}^{\mathbf{2}}\right)\end{array}$ & $\begin{array}{l}\text { Water Vapour } \\
\text { Permeance } \\
\mathrm{W}=\mathrm{g} / \mathrm{dp} \text { in } \mathrm{kg} / \\
\left(\mathrm{s} \times \mathrm{m}^{2} \times \mathrm{Pa}\right)\end{array}$ & $\begin{array}{c}\text { Water Vapour } \\
\text { Resistance } \\
\mathrm{Z}=1 / \mathrm{W} \text { in } \\
\left(\mathrm{s} \times \mathrm{m}^{2} \times \mathrm{Pa}\right) / \mathrm{kg}\end{array}$ & $\begin{array}{c}\text { Water Vapour } \\
\text { Permeability } \\
\mathcal{\delta}=W \times \mathrm{d} \text { in } \\
\mathrm{kg} /(\mathbf{s} \times \mathbf{m} \times \mathbf{P a})\end{array}$ & $\begin{array}{c}\text { Water } \\
\text { Vapour } \\
\text { Resistance } \\
\text { Factor } \mu\end{array}$ & $\begin{array}{c}\text { Diffusion- } \\
\text { Equivalent } \\
\text { Air Layer } \\
\text { Thickness } \\
\text { Sd }\end{array}$ \\
\hline & & & & & Dry cup test & & & & \\
\hline B-1 & 0.000449 & $2.0 \times 10^{-8}$ & 0.02745 & $7.4 \times 10^{-7}$ & $8.2 \times 10^{-10}$ & $1.2 \times 10^{9}$ & $3.7 \times 10^{-13}$ & 488.37 & 0.2193 \\
\hline B-2 & 0.000449 & $2.0 \times 10^{-8}$ & 0.02745 & $7.2 \times 10^{-7}$ & $8.0 \times 10^{-10}$ & $1.2 \times 10^{9}$ & $3.6 \times 10^{-13}$ & 499.37 & 0.2242 \\
\hline B-3 & 0.000479 & $2.1 \times 10^{-8}$ & 0.02686 & $8.0 \times 10^{-7}$ & $8.8 \times 10^{-10}$ & $1.1 \times 10^{9}$ & $4.2 \times 10^{-13}$ & 421.93 & 0.2021 \\
\hline B-4 & 0.000457 & $2.6 \times 10^{-8}$ & 0.02629 & $9.8 \times 10^{-7}$ & $1.1 \times 10^{-10}$ & $9.2 \times 10^{9}$ & $4.9 \times 10^{-13}$ & 352.68 & 0.1612 \\
\hline B-5 & 0.000476 & $1.7 \times 10^{-8}$ & 0.02629 & $6.5 \times 10^{-7}$ & $7.3 \times 10^{-10}$ & $1.4 \times 10^{9}$ & $3.5 \times 10^{-13}$ & 525.07 & 0.2499 \\
\hline Mean & 0.000462 & $2.1 \times 10^{-8}$ & 0.026868 & $7.8 \times 10^{-7}$ & $8.6 \times 10^{-10}$ & $1.2 \times 10^{9}$ & $4.0 \times 10^{-13}$ & 457.484 & 0.21134 \\
\hline B-6 & 0.000412 & $3.0 \times 10^{-8}$ & 0.02629 & $1.1 \times 10^{-6}$ & $7.0 \times 10^{-10}$ & $1.4 \times 10^{9}$ & $2.9 \times 10^{-13}$ & 611.33 & 0.2519 \\
\hline B-7 & 0.000472 & $3.0 \times 10^{-8}$ & 0.02572 & $1.2 \times 10^{-6}$ & $7.2 \times 10^{-10}$ & $1.4 \times 10^{9}$ & $3.4 \times 10^{-13}$ & 521.32 & 0.2461 \\
\hline B-8 & 0.000487 & $3.4 \times 10^{-8}$ & 0.02629 & $1.3 \times 10^{-6}$ & $8.0 \times 10^{-10}$ & $1.2 \times 10^{9}$ & $3.9 \times 10^{-13}$ & 447.98 & 0.2182 \\
\hline B-9 & 0.000468 & $3.6 \times 10^{-8}$ & 0.02804 & $1.3 \times 10^{-6}$ & $7.9 \times 10^{-10}$ & $1.3 \times 10^{9}$ & $3.7 \times 10^{-13}$ & 472.68 & 0.2213 \\
\hline B-10 & 0.000465 & $4.1 \times 10^{-8}$ & 0.02745 & $1.5 \times 10^{-6}$ & $9.3 \times 10^{-10}$ & $1.1 \times 10^{9}$ & $4.3 \times 10^{-13}$ & 400.86 & 0.1864 \\
\hline Mean & 0.0004608 & $3.4 \times 10^{-8}$ & 0.026758 & $1.3 \times 10^{-6}$ & $7.9 \times 10^{-10}$ & $1.3 \times 10^{9}$ & $3.6 \times 10^{-13}$ & 490.834 & 0.22478 \\
\hline
\end{tabular}


Table A6. Water vapour resistivity properties for sample B @ $23{ }^{\circ} \mathrm{C} 50 \% \mathrm{RH}$.

\begin{tabular}{|c|c|c|c|c|c|c|c|c|c|}
\hline $\begin{array}{c}\text { Sample } \\
\text { Tested } \\
@ 23{ }^{\circ} \mathrm{C} \\
50 \% \mathrm{RH}\end{array}$ & $\begin{array}{c}\text { Mean } \\
\text { Thickness } \\
\text { d (m) }\end{array}$ & $\begin{array}{l}\text { Mass } \\
\text { Change } \\
\text { Rate/Time } \\
\text { (G in kg/s) }\end{array}$ & $\underset{\mathbf{m}^{2}}{\operatorname{Area}}$ & $\begin{array}{c}\text { Water } \\
\text { Vapour Flux } \\
\mathrm{g}=\mathrm{G} / \mathrm{A} \text { in } \\
\mathrm{kg} /\left(\mathrm{s} \times \mathrm{m}^{\mathbf{2}}\right)\end{array}$ & $\begin{array}{c}\text { Water Vapour } \\
\text { Permeance } \\
\mathrm{W}=\mathrm{g} / \mathrm{dp} \text { in } \mathrm{kg} / \\
\left(\mathrm{s} \times \mathrm{m}^{2} \times \mathrm{Pa}\right)\end{array}$ & $\begin{array}{c}\text { Water Vapour } \\
\text { Resistance } \\
\mathrm{Z}=1 / \mathrm{W} \text { in } \\
\left(\mathrm{s} \times \mathrm{m}^{2} \times \mathrm{Pa}\right) / \mathrm{kg}\end{array}$ & $\begin{array}{c}\text { Water Vapour } \\
\text { Permeability } \\
\delta=W \times d \text { in } \\
\mathrm{kg} /(\mathrm{s} \times \mathrm{m} \times \mathrm{Pa})\end{array}$ & $\begin{array}{c}\text { Water } \\
\text { Vapour } \\
\text { Resistance } \\
\text { Factor } \mu\end{array}$ & $\begin{array}{c}\text { Diffusion- } \\
\text { Equivalent } \\
\text { Air Layer } \\
\text { Thickness } \\
\text { Sd }\end{array}$ \\
\hline B-1 & 0.000473 & $2.2 \times 10^{-8}$ & 0.0275 & $7.9 \times 10^{-7}$ & $\begin{array}{l}\text { Dry cup test } \\
6.0 \times 10^{-10}\end{array}$ & $1.7 \times 10^{9}$ & $2.8 \times 10^{-13}$ & 634.39 & 0.3001 \\
\hline B-2 & 0.000467 & $2.0 \times 10^{-8}$ & 0.02745 & $7.4 \times 10^{-7}$ & $5.9 \times 10^{-10}$ & $1.8 \times 10^{9}$ & $2.6 \times 10^{-13}$ & 695.09 & 0.325 \\
\hline B-3 & 0.00047 & $2.4 \times 10^{-8}$ & 0.02775 & $8.6 \times 10^{-7}$ & $6.5 \times 10^{-10}$ & $1.5 \times 10^{9}$ & $3.1 \times 10^{-13}$ & 583.59 & 0.274 \\
\hline B-4 & 0.000485 & $2.6 \times 10^{-8}$ & 0.02775 & $9.4 \times 10^{-7}$ & $7.1 \times 10^{-10}$ & $1.4 \times 10^{9}$ & $3.5 \times 10^{-13}$ & 512.54 & 0.2483 \\
\hline B-5 & 0.000478 & $2.4 \times 10^{-8}$ & 0.02775 & $8.6 \times 10^{-7}$ & $6.5 \times 10^{-10}$ & $1.5 \times 10^{9}$ & $3.1 \times 10^{-13}$ & 572.39 & 0.2736 \\
\hline Mean & 0.0004746 & $2.3 \times 10^{-8}$ & 0.02764 & $8.4 \times 10^{-7}$ & $\begin{array}{c}6.4 \times 10^{-10} \\
\text { Wet cup test }\end{array}$ & $1.6 \times 10^{9}$ & $3.0 \times 10^{-13}$ & 599.6 & 0.2842 \\
\hline B-6 & 0.000481 & $3.4 \times 10^{-8}$ & 0.027745 & $1.2 \times 10^{-6}$ & $1.0 \times 10^{-9}$ & $1.0 \times 10^{9}$ & $4.8 \times 10^{-13}$ & 355.59 & 0.171 \\
\hline B-7 & 0.00049 & $2.6 \times 10^{-8}$ & 0.02745 & $9.4 \times 10^{-7}$ & $7.8 \times 10^{-10}$ & $1.3 \times 10^{9}$ & $3.8 \times 10^{-13}$ & 464.12 & 0.2274 \\
\hline B-8 & 0.000462 & $4.2 \times 10^{-8}$ & 0.02745 & $1.5 \times 10^{-6}$ & $1.3 \times 10^{-9}$ & $7.8 \times 10^{8}$ & $5.9 \times 10^{-13}$ & 282.09 & 0.1303 \\
\hline B-9 & 0.000477 & $2.7 \times 10^{-8}$ & 0.028 & $9.6 \times 10^{-7}$ & $7.9 \times 10^{-10}$ & $1.3 \times 10^{9}$ & $3.8 \times 10^{-13}$ & 465.67 & 0.2221 \\
\hline B-10 & 0.000461 & $4.5 \times 10^{-8}$ & 0.02745 & $1.6 \times 10^{-6}$ & $1.4 \times 10^{-9}$ & $7.3 \times 10^{8}$ & $6.3 \times 10^{-13}$ & 262.034 & 0.121 \\
\hline Mean & 0.0004742 & $3.5 \times 10^{-8}$ & 0.027619 & $1.3 \times 10^{-6}$ & $1.0 \times 10^{-9}$ & $1.0 \times 10^{9}$ & $4.9 \times 10^{-13}$ & 365.9008 & 0.17436 \\
\hline
\end{tabular}

Table A7. Water vapour resistivity properties for sample B @ $23{ }^{\circ} \mathrm{C} 65 \% \mathrm{RH}$.

\begin{tabular}{|c|c|c|c|c|c|c|c|c|c|}
\hline $\begin{array}{l}\text { Sample } \\
\text { Tested } \\
@ 23 \circ \mathrm{C} \\
65 \% \mathrm{RH}\end{array}$ & $\begin{array}{c}\text { Mean } \\
\text { Thickness } \\
\text { d }(\mathrm{m})\end{array}$ & $\begin{array}{l}\text { Mass } \\
\text { Change } \\
\text { Rate/Time } \\
\text { (G in kg/s) }\end{array}$ & $\underset{\mathrm{m}^{2}}{\operatorname{Area}}$ & $\begin{array}{c}\text { Water } \\
\text { Vapour Flux } \\
\mathrm{g}=\mathrm{G} / \mathrm{A} \text { in } \\
\mathrm{kg} /\left(\mathrm{s} \times \mathrm{m}^{\mathbf{2}}\right)\end{array}$ & $\begin{array}{l}\text { Water Vapour } \\
\text { Permeance } \\
\mathrm{W}=\mathrm{g} / \mathrm{dp} \text { in } \mathrm{kg} / \\
\left(\mathbf{s} \times \mathrm{m}^{\mathbf{2}} \times \mathrm{Pa}\right)\end{array}$ & $\begin{array}{c}\text { Water Vapour } \\
\text { Resistance } \\
\mathrm{Z}=1 / \mathrm{W} \text { in } \\
\left(\mathrm{s} \times \mathrm{m}^{2} \times \mathrm{Pa}\right) / \mathrm{kg}\end{array}$ & $\begin{array}{c}\text { Water Vapour } \\
\text { Permeability } \\
\delta=W \times d \text { in } \\
\mathrm{kg} /(\mathbf{s} \times \mathbf{m} \times \mathbf{P a})\end{array}$ & $\begin{array}{c}\text { Water } \\
\text { Vapour } \\
\text { Resistance } \\
\text { Factor } \mu\end{array}$ & $\begin{array}{c}\text { Diffusion- } \\
\text { Equivalent } \\
\text { Air Layer } \\
\text { Thickness } \\
\text { Sd }\end{array}$ \\
\hline & & & & & Dry cup test & & & & \\
\hline B-1 & 0.000446 & $3.6 \times 10^{-8}$ & 0.0275 & $1.3 \times 10^{-6}$ & $7.5 \times 10^{-10}$ & $1.3 \times 10^{9}$ & $3.3 \times 10^{-13}$ & 547.89 & 0.2444 \\
\hline B-2 & 0.000454 & $4.4 \times 10^{-8}$ & 0.0284 & $1.6 \times 10^{-6}$ & $8.9 \times 10^{-10}$ & $1.1 \times 10^{9}$ & $4.0 \times 10^{-13}$ & 442.91 & 0.2011 \\
\hline B-3 & 0.00045 & $4.2 \times 10^{-8}$ & 0.02778 & $1.5 \times 10^{-6}$ & $8.7 \times 10^{-10}$ & $1.2 \times 10^{9}$ & $3.9 \times 10^{-13}$ & 459.47 & 0.2068 \\
\hline B-4 & 0.000464 & $4.2 \times 10^{-8}$ & 0.0269 & $1.6 \times 10^{-6}$ & $9.0 \times 10^{-10}$ & $1.1 \times 10^{9}$ & $4.2 \times 10^{-13}$ & 326.97 & 0.1981 \\
\hline B-5 & 0.000455 & $4.1 \times 10^{-8}$ & 0.0275 & $1.5 \times 10^{-6}$ & $8.5 \times 10^{-10}$ & $1.2 \times 10^{9}$ & $3.9 \times 10^{-13}$ & 463.78 & 0.2110 \\
\hline Mean & 0.0004538 & $4.1 \times 10^{-8}$ & 0.0276 & $1.5 \times 10^{-6}$ & $\begin{array}{l}8.5 \times 10^{-10} \\
\text { Wet cup test }\end{array}$ & $1.2 \times 10^{9}$ & $3.9 \times 10^{-13}$ & 448.204 & 0.2123 \\
\hline B-6 & 0.000445 & $2.1 \times 10^{-8}$ & 0.0275 & $7.7 \times 10^{-7}$ & $9.7 \times 10^{-10}$ & $1.0 \times 10^{9}$ & $4.3 \times 10^{-13}$ & 405 & 0.1803 \\
\hline B-7 & 0.000445 & $2.0 \times 10^{-8}$ & 0.0281 & $7.1 \times 10^{-7}$ & $9.0 \times 10^{-10}$ & $1.1 \times 10^{9}$ & $4.0 \times 10^{-13}$ & 440.52 & 0.196 \\
\hline B-8 & 0.000458 & $2.2 \times 10^{-8}$ & 0.0275 & $8.1 \times 10^{-7}$ & $1.0 \times 10^{-9}$ & $9.7 \times 10^{8}$ & $4.7 \times 10^{-13}$ & 368.78 & 0.1689 \\
\hline B-9 & 0.00044 & $2.6 \times 10^{-8}$ & 0.0275 & $9.5 \times 10^{-7}$ & $1.2 \times 10^{-9}$ & $8.3 \times 10^{8}$ & $5.3 \times 10^{-13}$ & 322.8 & 0.142 \\
\hline B-10 & 0.000447 & $2.5 \times 10^{-8}$ & 0.02778 & $9.0 \times 10^{-7}$ & $1.1 \times 10^{-9}$ & $8.8 \times 10^{8}$ & $5.1 \times 10^{-13}$ & 338.42 & 0.121 \\
\hline Mean & 0.000447 & $2.3 \times 10^{-8}$ & 0.0278 & $8.3 \times 10^{-7}$ & $1.1 \times 10^{-9}$ & $9.6 \times 10^{8}$ & $1.1 \times 10^{-13}$ & 375.104 & 0.16164 \\
\hline
\end{tabular}

Table A8. Water vapour resistivity properties for sample B @23 ${ }^{\circ} \mathrm{C} 80 \% \mathrm{RH}$.

\begin{tabular}{|c|c|c|c|c|c|c|c|c|c|}
\hline $\begin{array}{l}\text { Sample } \\
\text { Tested } \\
@ 23{ }^{\circ} \mathrm{C} \\
80 \% \mathrm{RH}\end{array}$ & $\begin{array}{c}\text { Mean } \\
\text { Thickness } \\
\text { d (m) }\end{array}$ & $\begin{array}{l}\text { Mass } \\
\text { Change } \\
\text { Rate/Time } \\
\text { (G in kg/s) }\end{array}$ & $\underset{\mathrm{m}^{2}}{\text { Area }}$ & $\begin{array}{c}\text { Water } \\
\text { Vapour Flux } \\
\mathrm{g}=\mathrm{G} / \mathrm{A} \text { in } \\
\mathrm{kg} /\left(\mathrm{s} \times \mathrm{m}^{\mathbf{2}}\right)\end{array}$ & $\begin{array}{l}\text { Water Vapour } \\
\text { Permeance } \\
\mathrm{W}=\mathrm{g} / \mathrm{dp} \text { in } \mathrm{kg} / \\
\left(\mathrm{s} \times \mathrm{m}^{2} \times \mathrm{Pa}\right)\end{array}$ & $\begin{array}{c}\text { Water Vapour } \\
\text { Resistance } \\
\mathrm{Z}=1 / \mathrm{W} \text { in } \\
\left(\mathrm{s} \times \mathrm{m}^{2} \times \mathrm{Pa}\right) / \mathrm{kg}\end{array}$ & $\begin{array}{l}\text { Water Vapour } \\
\text { Permeability } \\
\delta=W \times d \text { in } \\
\mathrm{kg} /(\mathbf{s} \times \mathbf{m} \times \mathbf{P a})\end{array}$ & $\begin{array}{c}\text { Water } \\
\text { Vapour } \\
\text { Resistance } \\
\text { Factor } \mu\end{array}$ & $\begin{array}{c}\text { Diffusion- } \\
\text { Equivalent } \\
\text { Air Layer } \\
\text { Thickness } \\
\text { Sd }\end{array}$ \\
\hline B-1 & 0.000454 & $5.8 \times 10^{-8}$ & 0.0284 & $2.0 \times 10^{-6}$ & $\begin{array}{l}\text { Dry cup test } \\
9.4 \times 10^{-10}\end{array}$ & $1.1 \times 10^{9}$ & $4.3 \times 10^{-13}$ & 409 & 0.1861 \\
\hline B-2 & 0.000456 & $5.2 \times 10^{-8}$ & 0.0272 & $1.9 \times 10^{-6}$ & $8.8 \times 10^{-10}$ & $1.1 \times 10^{9}$ & $4.0 \times 10^{-13}$ & 437.96 & 0.1997 \\
\hline B-3 & 0.000464 & $5.2 \times 10^{-8}$ & 0.0275 & $1.9 \times 10^{-6}$ & $8.7 \times 10^{-10}$ & $1.2 \times 10^{9}$ & $4.0 \times 10^{-13}$ & 438.79 & 0.2036 \\
\hline B-4 & 0.000468 & $5.1 \times 10^{-8}$ & 0.0275 & $1.9 \times 10^{-6}$ & $8.6 \times 10^{-10}$ & $1.2 \times 10^{9}$ & $4.0 \times 10^{-13}$ & 440.36 & 0.2061 \\
\hline B-5 & 0.000461 & $5.3 \times 10^{-8}$ & 0.0278 & $1.9 \times 10^{-6}$ & $8.8 \times 10^{-10}$ & $1.1 \times 10^{9}$ & $4.0 \times 10^{-13}$ & 436.21 & 0.2011 \\
\hline Mean & 0.000461 & $5.3 \times 10^{-8}$ & 0.02768 & $1.9 \times 10^{-6}$ & $\begin{array}{l}8.9 \times 10^{-10} \\
\text { Wet cup test }\end{array}$ & $1.1 \times 10^{9}$ & $4.1 \times 10^{-13}$ & 432.464 & 0.19932 \\
\hline B-6 & 0.000458 & $9.9 \times 10^{-9}$ & 0.0278 & $3.6 \times 10^{-7}$ & $9.8 \times 10^{-10}$ & $1.0 \times 10^{9}$ & $4.5 \times 10^{-13}$ & 365.99 & 0.1676 \\
\hline B-7 & 0.000456 & $9.3 \times 10^{-9}$ & 0.0275 & $3.4 \times 10^{-7}$ & $9.2 \times 10^{-10}$ & $1.1 \times 10^{9}$ & $4.2 \times 10^{-13}$ & 419.08 & 0.1911 \\
\hline B-8 & 0.000459 & $9.3 \times 10^{-9}$ & 0.0272 & $3.4 \times 10^{-7}$ & $9.3 \times 10^{-10}$ & $1.1 \times 10^{9}$ & $4.3 \times 10^{-13}$ & 411.16 & 0.1887 \\
\hline B-9 & 0.000468 & $9.4 \times 10^{-9}$ & 0.0275 & $3.4 \times 10^{-7}$ & $9.4 \times 10^{-10}$ & $1.1 \times 10^{9}$ & $4.4 \times 10^{-13}$ & 402.45 & 0.1884 \\
\hline B-10 & 0.000455 & $8.9 \times 10^{-9}$ & 0.0275 & $3.2 \times 10^{-7}$ & $8.8 \times 10^{-10}$ & $1.1 \times 10^{9}$ & $4.0 \times 10^{-13}$ & 442.24 & 0.2012 \\
\hline Mean & 0.000459 & $9.3 \times 10^{-9}$ & 0.0275 & $3.4 \times 10^{-7}$ & $9.3 \times 10^{-10}$ & $1.1 \times 10^{9}$ & $4.3 \times 10^{-13}$ & 408.184 & 0.1874 \\
\hline
\end{tabular}




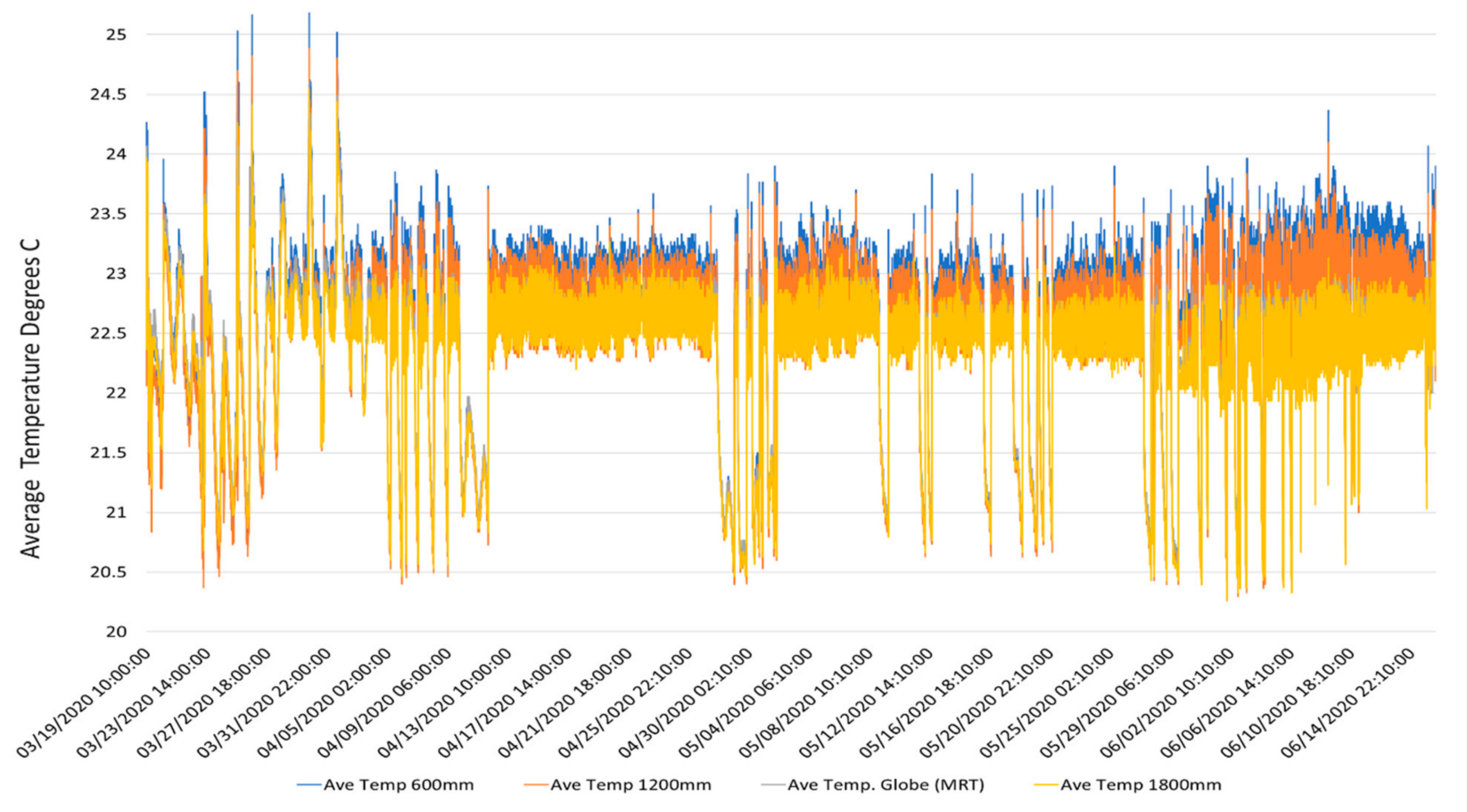

Figure A1. Temperature profile of the hygrothermal room aimed at $23^{\circ} \mathrm{C}$ for the testing period 1.

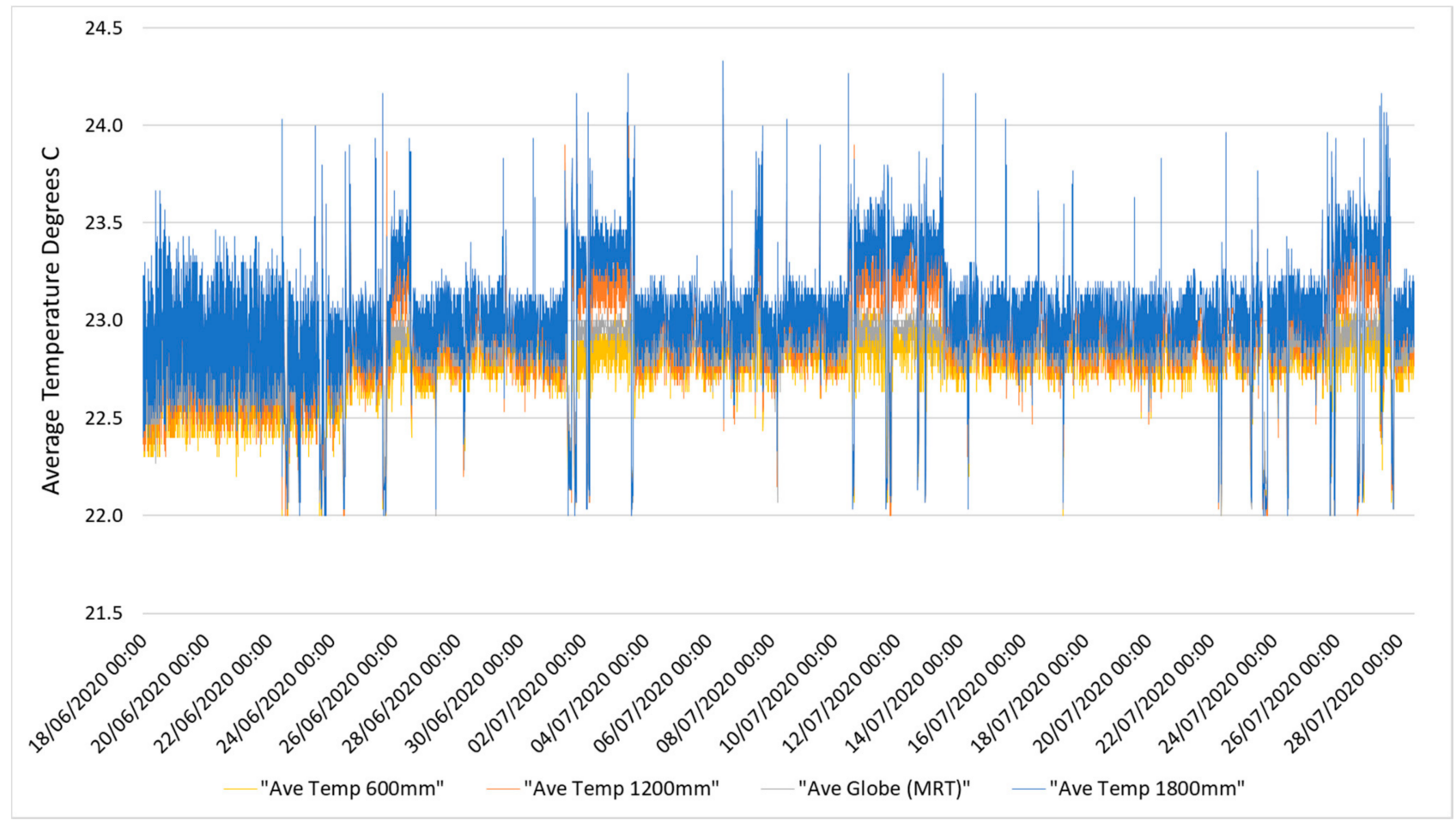

Figure A2. Temperature profile of the hygrothermal room aimed at $23^{\circ} \mathrm{C}$ for the testing period 2 . 


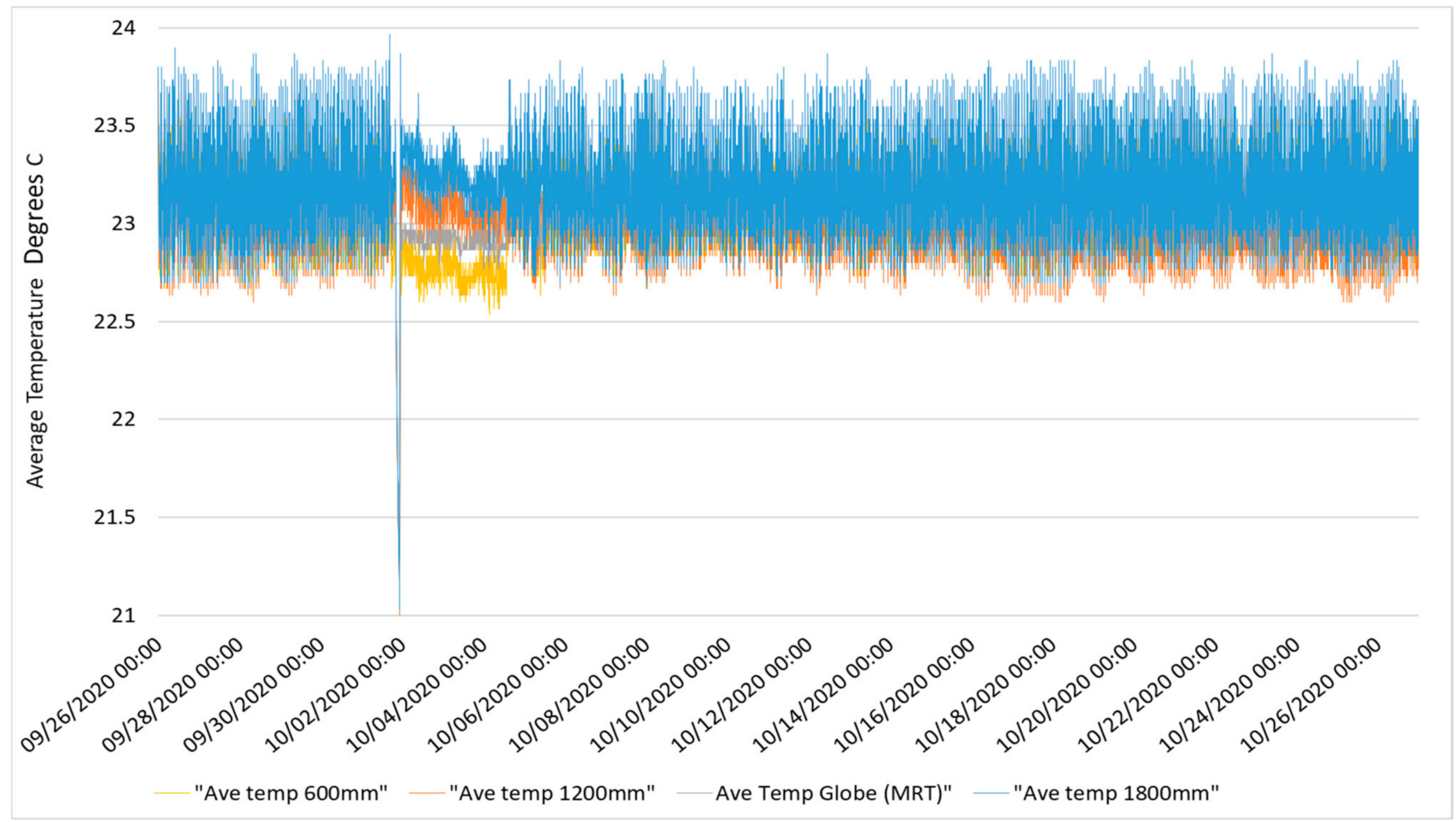

Figure A3. Temperature profile of the hygrothermal room aimed at $23^{\circ} \mathrm{C}$ for the testing period 3 .

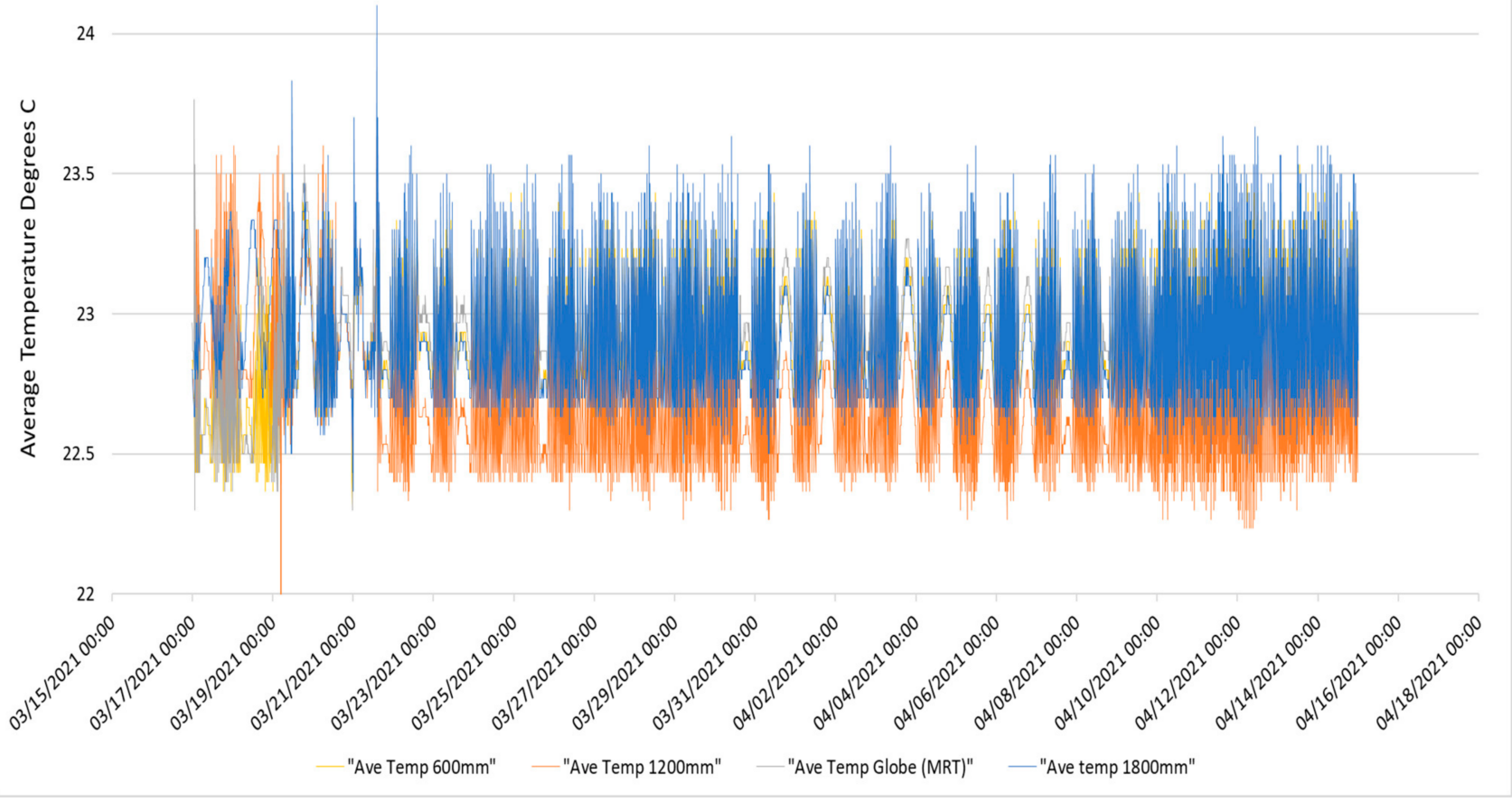

Figure A4. Temperature profile of the hygrothermal room aimed at $23^{\circ} \mathrm{C}$ for the testing period 4 . 


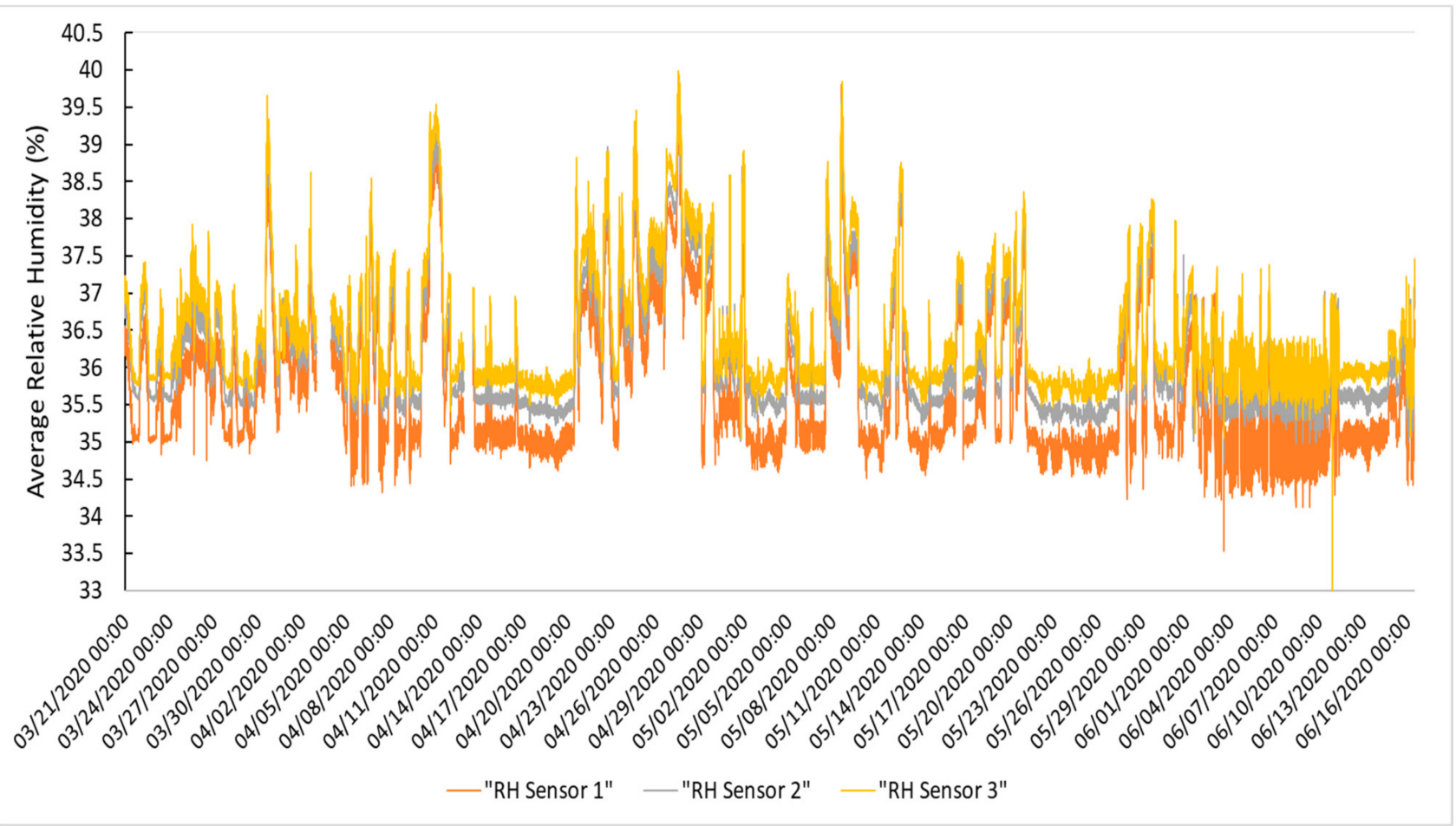

Figure A5. Relative humidity profile of the room aimed at 35\% for the testing period 1.

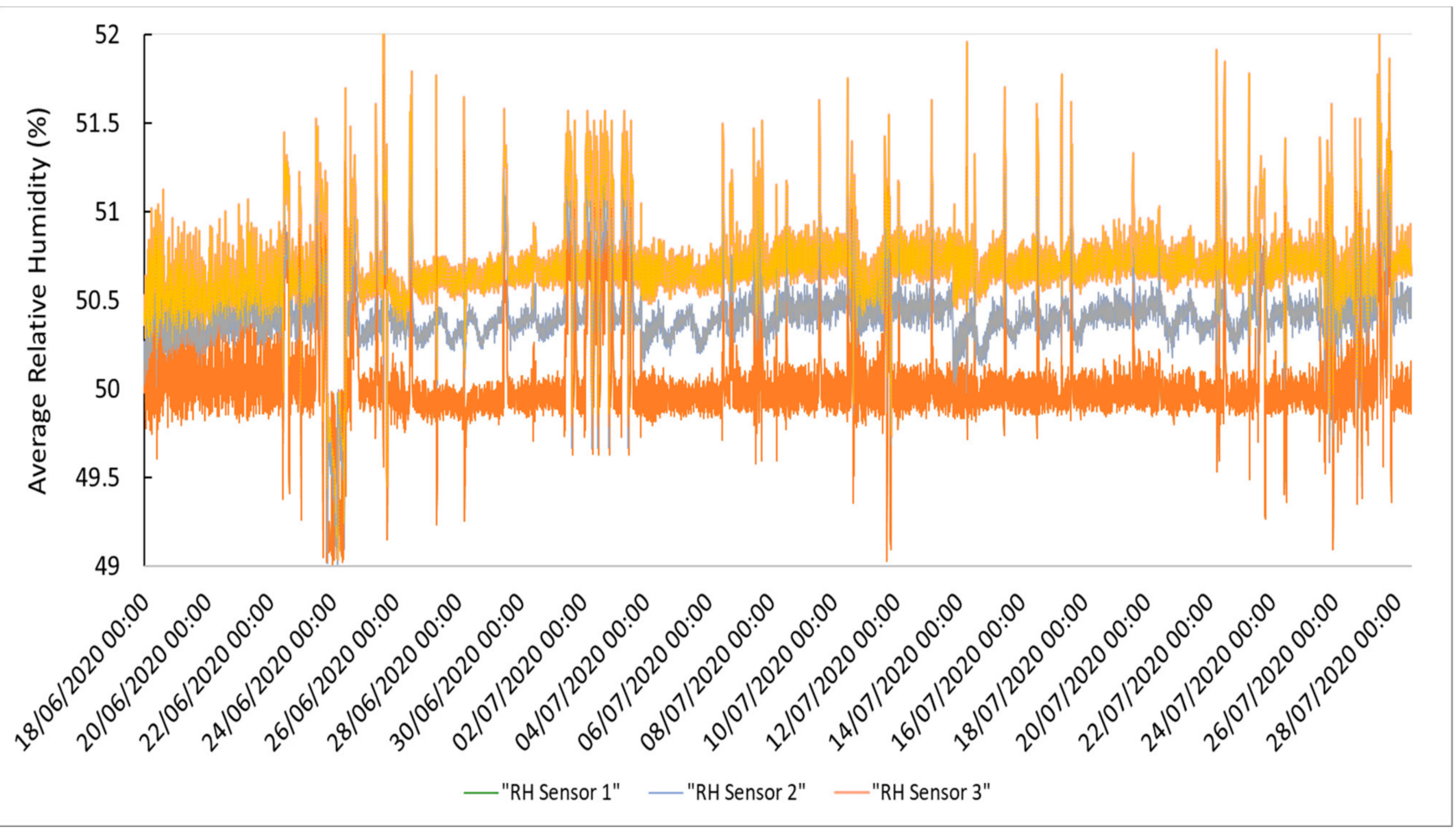

Figure A6. Relative humidity profile of the room aimed at 50\% for the testing period 2. 


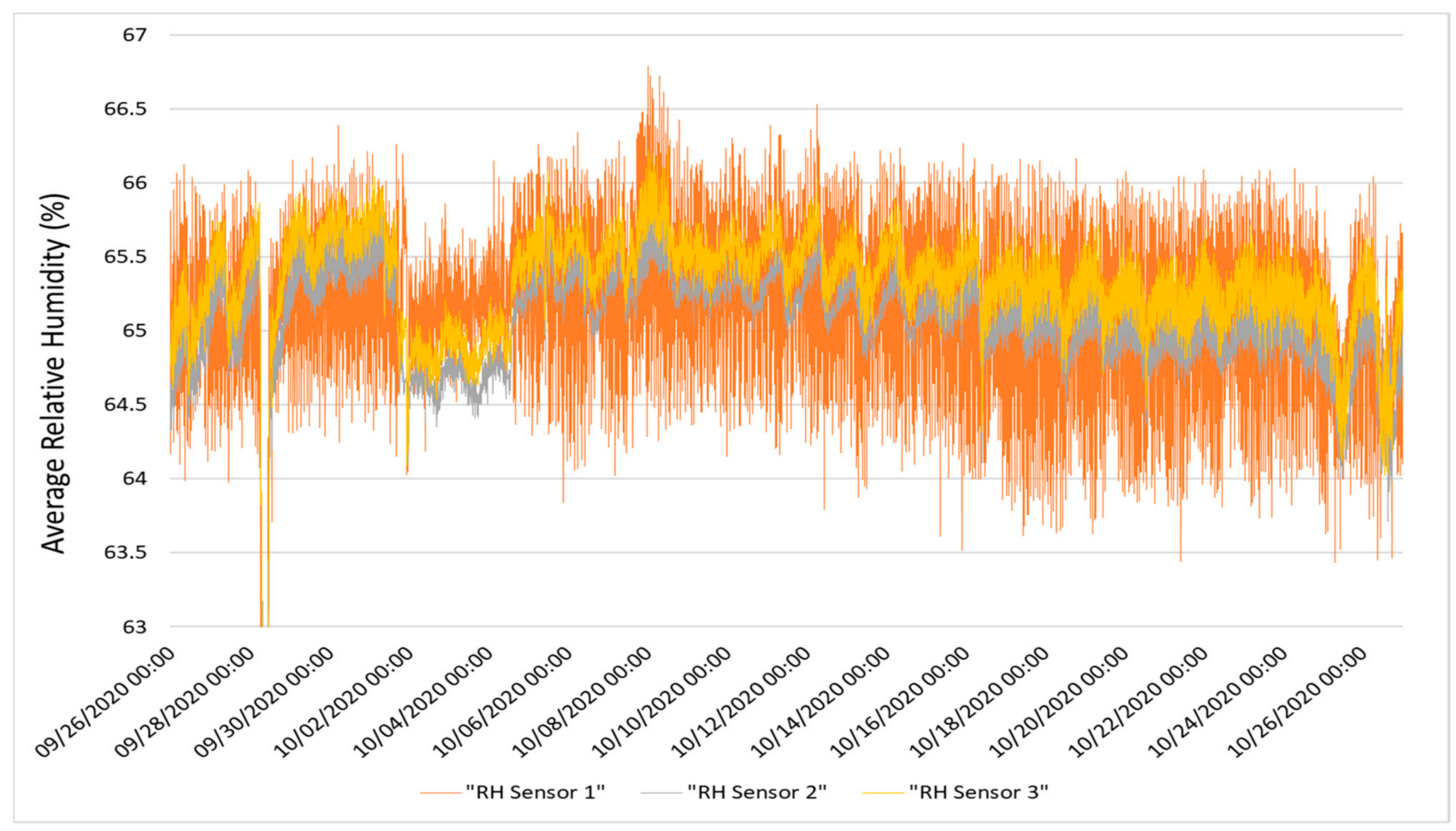

Figure A7. Relative humidity profile of the room aimed at $65 \%$ for the testing period 3.

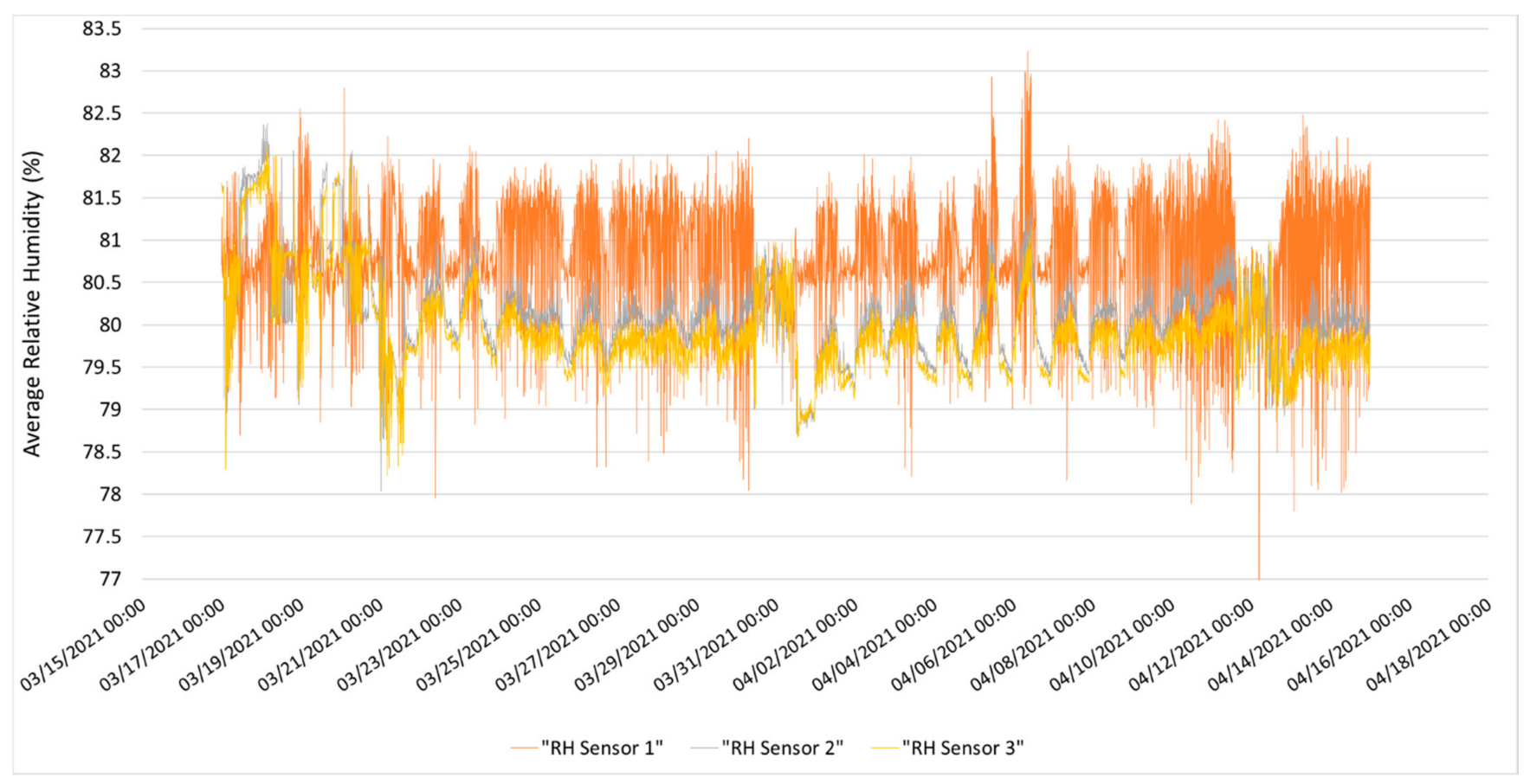

Figure A8. Relative humidity profile of the room aimed at $80 \%$ for the testing period 4.

\section{References}

1. Baker, P.H.; Galbraith, G.H.; McLean, R.C. Temperature gradient effects on moisture transport in porous building materials. Build. Serv. Eng. Res. Technol. 2009, 30, 37-48. [CrossRef]

2. Olaoye, T.S.; Dewsbury, M.; Kunzel, H.; Nolan, G. An empirical measurement of the water vapour resistivity properties of typical australian pliable membrane. In Proceedings of the 54th International Conference of the Architectural Science Association (ANZAScA), Auckland, New Zealand, 25-28 November 2020. 
3. Valovirta, I.; Vinha, J. Water Vapor Permeability and Thermal Conductivity as a Function of Temperature and Relative Humidity. In Performance of Exterior Envelopes of Whole Buildings, Proceedings of the IX International Conference, Florida, FL, USA, 5-10 December 2004; ASHRAE: Atlanta, GA, USA, 2004.

4. Couturier, M.; Boucher, C. Dynamic water vapor permeance of building materials and the benefits to buildings. In Proceedings of the 26th RCI International convention and trades show, Reno, NY, USA, 7-12 April 2011.

5. ASTM. Standard test methods for water vapor transmission of materials. In E96/E96M; ASTM International: West Conshohocken, PA, USA, 2010.

6. ISO. International Standard Organization EN. Hygrothermal Performance of Building Materials and Products-Determination of Water Vapour Transmission Properties-Cup Method ISO 12572. In EVS-EN ISO 12572:2016; Estonian Centre or Standardization: Brussels, Belgium, 2016.

7. Viljanen, K.; Lu, X. An Experimental Study on the Drying-Out Ability of Highly Insulated Wall Structures with Built-In Moisture and Rain Leakage. Appl. Sci. 2019, 9, 1222. [CrossRef]

8. Bomberg, M.; Furtak, M.; Yarbrough, D. Buildings with environmental quality management: Part 1: Designing multifunctional construction materials. J. Build. Phys. 2017, 41, 193-208. [CrossRef]

9. Nath, S.; Dewsbury, M.; Orr, K. Is New Housing Health Hazard? In Engaging Architectural Science: Meeting the Challenges of Higher Density, Proceedings of the 52nd International Conference of the Architectural Science Association, Melbourne, Australia, 28 November-1 December 2018; RMIT University: Melbourne, Australia, 2018.

10. Olaoye, T.S.; Dewsbury, M.; Kunzel, H. A Method for Establishing a Hygrothermally Controlled Test Room for Measuring the Water Vapor Resistivity Characteristics of Construction Materials. Energies 2020, 14, 4. [CrossRef]

11. WHO. WHO Guidelines for Indoor Air Quality: Dampness and Mould; WHO Regional Office for Europe: Copenhagen, Denmark, 2009.

12. Arman, H.; Narguess, K. The Effects of Air Permeability, Background Ventilation and Lifestyle on Energy Performance, Indoor Air Quality and Risk of Condensation in Domestic Buildings. Sustainability 2015, 7, 4022-4034.

13. Jensen, N.F.; Bjarløv, S.P.; Rode, C.; Andersen, B.; Møller, E.B. Hygrothermal performance of six insulation systems for internal retrofitting solid masonry walls. J. Build. Phys. 2021, 44, 539-573. [CrossRef]

14. Kaynakli, Ö.; Bademlioglu, A.H.; Ufat, H.T. Determination of optimum insulation thickness for different insulation applications considering condensation. Teh. Vjesn. Tech. Gaz. 2018, 25, 32-42.

15. Fořt, J.; Šál, J.; Kočí, J.; Černý, R. Energy efficiency of novel interior surface layer with improved thermal characteristics and its effect on hygrothermal performance of contemporary building envelopes. Energies 2020, 13, 2012. [CrossRef]

16. Künzel, H.M.; Zirkelbach, D. Advances in hygrothermal building component simulation: Modelling moisture sources likely to occur due to rainwater leakage. J. Build. Perform. Simul. 2013, 6, 346-353. [CrossRef]

17. Langmans, J.; Klein, R.; Roels, S. Numerical and experimental investigation of the hygrothermal response of timber frame walls with an exterior air barrier. J. Build. Phys. 2013, 36, 375-397. [CrossRef]

18. Wanghee, C.; Shizuo, I.; Shinsuke, K. Condensation Risk Due to Variations in Airtightness and Thermal Insulation of an Office Building in Warm and Wet Climate. Energies 2016, 9, 875.

19. Woloszyn, M.; Rode, C. Tools for performance simulation of heat, air and moisture conditions of whole buildings. Build. Simul. 2008, 1, 5-24. [CrossRef]

20. ANSI/ASHRAE. Criteria for moisture-control design analysis in buildings. In ASHRAE Standard 160; American Society of Heating, Refrigerating and Air-Conditioning Engineers: Atlanta, GA, USA, 2009.

21. AIRAH. Criteria for moisture control design analysis in buildings. In DA07; Australian Institute of Refrigeration, Air Conditioning and Heating: Melbourne, Australia, 2020.

22. Künzel, H.M. Adapted vapour control for durable building enclosures. In Proceedings of the 10th International Conference on Durability of Building Materials \& Components, Lyon, France, 17-20 April 2005.

23. Künzel, H.M.; Zirkelbach, D.; Sedlbauer, K. Predicting indoor temperature and humidity conditions including hygrothermal interactions with the building envelope. In Proceedings of the 1st International Conference on Sustainable Energy and Green Architecture, Building Scientific Research Center (BSRC), King Mongkut's University Thonburi Bangkok, Bangkok, Thailand, 8-10 October 2003.

24. Torres-Ramo, J.; González-Martínez, P.; Arriazu-Ramos, N.; Sánchez-Ostiz, A. Influence of the Water Vapour Permeability of Airtight Sheets on the Behaviour of Facade. Sustainability 2020, 12, 10480. [CrossRef]

25. Mukhopadhyaya, P.M.; Kumaran, K.; Lackey, J.; Normandin, N.; van Reenen, D.; Tariku, F. Hygrothermal Properties of Exterior Claddings, Sheathing Boards, Membranes, and Insulation Materials for Building Envelope Design; ASHRAE: Atlanta, GA, USA, 2007.

26. Dewsbury, M.; Law, T.; Potgieter, J.; Fitzgerald, D.; McComish, B.; Chandler, T.; Soudan, A. Scoping Study of Condensation in Residential Buildings: Final Report; Department of Industry Innovation and Science, Australian Building Codes Board: Canberra, Australia, 2016.

27. Dewsbury, M.; Soudan, A.; Su, F.; Geard, D.; Cooper, A.; Law, T. Condensation Risk Mitigation for Tasmanian Housing; Department of Justice Tasmania: Hobart, Australia, 2018.

28. AS/NZS. Pliable building membranes and underlays. In AS/NZS 4200:1; Council of Standards Australia: Sydney, Australia; SAI Global Limited and Standards: Auckland, New Zealand, 2017.

29. Olaoye, T.S.; Dewsbury, M. Australian building materials and vapour resistivity. In Building Physics Forum; AIRAH: Wollogong, Australia, 2018. 
30. Olaoye, T.S.; Dewsbury, M. Establishing an Environmentally Controlled Room to Quantify Water Vapour Resistivity Properties of Construction Materials. In Revisiting the Role of Architecture for 'Surviving' Development, Proceedings of the 53rd International Conference of the Architectural Science Association 2019, Roorkee, India, 28-30 November 2019; Agrawal, A., Gupta, R., Eds.; Architectural Science Association (ANZAScA): Auckland, New Zealand, 2019; pp. 675-684.

31. ABCB. Ncc 2019 Building Code of Australia; Australia Building Code Board: Canberra, Australia, 2019 ; Volume 2. 